\title{
Firing Properties of Rat Lateral Mammillary Single Units: Head Direction, Head Pitch, and Angular Head Velocity
}

\author{
Robert W. Stackman and Jeffrey S. Taube \\ Department of Psychology, Dartmouth College, Hanover, New Hampshire 03755
}

Many neurons in the rat anterodorsal thalamus (ADN) and postsubiculum (PoS) fire selectively when the rat points its head in a specific direction in the horizontal plane, independent of the animal's location and ongoing behavior. The lateral mammillary nuclei (LMN) are interconnected with both the ADN and PoS and, therefore, are in a pivotal position to influence ADN/PoS neurophysiology. To further understand how the head direction (HD) cell signal is generated, we recorded single neurons from the LMN of freely moving rats. The majority of cells discharged as a function of one of three types of spatial correlates: (1) directional heading, (2) head pitch, or (3) angular head velocity (AHV). LMN HD cells exhibited higher peak firing rates and greater range of directional firing than that of ADN and PoS HD cells. LMN HD cells were modulated by angular head velocity, turning direction, and anticipated the rat's future HD by a greater amount of time $(\sim 95 \mathrm{msec})$ than that previously re- ported for ADN HD cells ( $25 \mathrm{msec})$. Most head pitch cells discharged when the rostrocaudal axis of the rat's head was orthogonal to the horizontal plane. Head pitch cell firing was independent of the rat's location, directional heading, and its body orientation (i.e., the cell discharged whenever the rat pointed its head up, whether standing on all four limbs or rearing). AHV cells were categorized as fast or slow AHV cells depending on whether their firing rate increased or decreased in proportion to angular head velocity. These data demonstrate that LMN neurons code direction and angular motion of the head in both horizontal and vertical planes and support the hypothesis that the LMN play an important role in processing both egocentric and allocentric spatial information.

Key words: mammillary nuclei; head direction cell; directional heading; angular head velocity; head pitch; spatial navigation; limbic system; anterior thalamus; postsubiculum
Navigation requires the encoding and maintenance of representations regarding the spatial relationship of the organism to its environment (location and directional heading). Allocentric representations of spatial location and direction are thought to be processed by an integrated multimodal circuit within the limbic system. Several neural regions process and encode distinct types of spatial information. Hippocampal principal neurons discharge as a function of spatial location (O'Keefe, 1976; Muller et al., 1987), whereas posterior parietal cortical neurons provide the perception of the spatial location of distinct objects (Andersen et al., 1985). Neurons found in the rat postsubiculum (PoS) (Taube et al., 1990a,b) and anterodorsal thalamic nucleus (ADN) (Taube, 1995) discharge as a function of directional heading in the horizontal plane, independent of location or other ongoing behaviors. Each of these head direction (HD) cells fires maximally at one directional heading, referred to as the preferred direction. HD cells have also been identified in the lateral dorsal nucleus of thalamus (Mizumori and Williams, 1993); striatum (Wiener, 1993; Mizumori and Cooper, 1995); and retrosplenial and medial prestriate cortices (Chen et al., 1994). The organization of a central representation of directional bearing undoubtedly requires the coordinated integration of neural signals from several

Received June 9, 1998; revised Aug. 5, 1998; accepted Aug. 11, 1998.

This work was supported by the National Institute on Deafness and Other Communication Disorders Grant DC00236 to R.W.S., and the National Institute of Mental Health Grants MH48924 and MH01286 to J.S.T. We thank M. Tullman and C. Leonhard for assistance with training rats and recording single units, and Dr. Jeremy Goodridge for numerous lengthy discussions of these data.

A preliminary report of this research was presented at the 26th Annual Society for Neuroscience meeting in Washington, DC in 1996.

Correspondence should be addressed to Dr. Jeffrey S. Taube, Department of Psychology, Dartmouth College, 6207 Gerry Hall, Hanover, NH 03755-3549.

Copyright (C) 1998 Society for Neuroscience $0270-6474 / 98 / 189020-18 \$ 05.00 / 0$ brain areas. Understanding the circuitry conveying the HD cell signal is an important first step in elucidating the neural mechanisms of a sense of directional heading.

In rats, the PoS is reciprocally connected with the $\mathrm{ADN}$, lateral dorsal thalamic nucleus, and retrosplenial cortex (Swanson and Cowan, 1977; van Groen and Wyss, 1990, 1992, 1995; Shibata, 1993). HD cell firing is abolished in the PoS after neurotoxic ADN lesions (Goodridge and Taube, 1997), suggesting that the HD cell signal may be generated in the ADN (or areas afferent to it) and conveyed to the PoS. We recently reported that lesions of the vestibular apparatus disrupt directional firing of ADN neurons demonstrating the critical role of vestibular information in HD cell activity (Stackman and Taube, 1997). Vestibular information arising from brainstem vestibular nuclei could reach the ADN via at least two polysynaptic pathways. The vestibular nuclei project primarily to the medial geniculate nucleus and the ventral posterior inferior thalamic nucleus (Abraham et al., 1977; Lang et al., 1979). These thalamic areas project to the parietoinsular vestibular cortex in nonhuman primates (Büttner and Lang, 1979; Grüsser et al., 1990). Thus, the ADN could receive vestibular information via a corticofugal pathway from the parietoinsular cortex to retrosplenial cortex, and in turn to the ADN directly, or indirectly via the Pos (see Fig. 10). Alternatively, the rat medial vestibular nuclei, which encode primarily horizontal semicircular canal information, project directly to the dorsal tegmental nucleus (Liu et al., 1984). The dorsal tegmental nucleus innervates the lateral mammillary nuclei (LMN) (Shibata, 1987; Allen and Hopkins, 1989; Gonzalo-Ruiz et al., 1992), which are reciprocally connected to the ADN (Hayakawa and Zyo, 1989; Shibata, 1992; Guison et al., 1995). The LMN also receive input from the PoS (Allen and Hopkins, 1989; Shibata, 1989). As a component of the 
mammillary complex, the LMN may be in a unique position to affect allocentric spatial information processing via an influence on HD cell activity as an element of a tripartite circuit that includes the ADN and PoS. Accordingly, lesions of the mammillary complex produce impairments in spatial memory processing (Aggleton et al., 1990; Neave et al., 1997; Sziklas and Petrides, 1998). Therefore, the present experiment examined the spatial correlates of LMN neurons recorded from freely moving rats. Our results show that most LMN cells displayed one of three types of spatial correlates: (1) directional heading in azimuth, (2) head pitch, or (3) angular head velocity.

\section{MATERIALS AND METHODS}

Subjects and training. Subjects were 17 female Long-Evans rats, weighing 250-300 gm at the beginning of the experiment. Rats were maintained on a food-restricted diet (15-20 gm/d) and housed separately in suspended wire mesh cages. Tap water was available ad libitum. All training, unit screening, and recording occurred during sessions in which the rats foraged for food pellets in a gray cylindrical apparatus $(76 \mathrm{~cm}$ diameter, $51 \mathrm{~cm}$ high). A black floor-to-ceiling curtain enclosure (2 $\mathrm{m}$ diameter) surrounded the cylinder, and four uniformly arranged overhead DC lamps provided illumination. A color video camera (model XC-711; Sony, Tokyo, Japan) was centered above the cylinder $3 \mathrm{~m}$ from the floor surface. The cylinder was placed on a sheet of gray photographic backdrop paper. A white cue card attached to the inside wall of the cylinder, occupying $\sim 100^{\circ}$ of arc, served as a visual landmark. Rats received at least five training trials $(1 \mathrm{trial} / \mathrm{d})$ during which food pellets $(20 \mathrm{mg}$, PJ Noyes, Lancaster, $\mathrm{NH}$ ) were thrown randomly into the cylinder. By the completion of training, rats engaged in nearly continuous food pellet search behavior over the entire floor of the cylinder. All procedures involving the rats were performed in compliance with institutional standards as set forth by the National Institutes of Health Guide for the Care and Use of Laboratory Animals and the Society for Neuroscience.

Electrode implantation. Electrode construction and implantation techniques used were similar to those described previously (Taube, 1995). Briefly, each electrode array consisted of a bundle of ten $25-\mu \mathrm{m}-$ diameter, nichrome wires (California Fine Wire Co., Grover City, CA) insulated except at the tips. The wire bundle was passed through a 26 gauge stainless steel cannula (27 $\mathrm{mm}$ in length) and each wire attached to a modified 11-pin Augat connector. The electrode array could be advanced in the dorsoventral plane through the use of three screws attached to the acrylic base of the electrode (Kubie, 1984). After habituation to the cylindrical apparatus and the expression of adequate food pellet foraging behavior, each rat was anesthetized with a ketaminexylazine mixture $(2 \mathrm{ml} / \mathrm{kg}$; i.m.) and stereotaxically implanted with an electrode array directed at the LMN of either the left or right side. Electrode coordinates were as follows: from bregma: anteroposterior, $-4.6 \mathrm{~mm}$; mediolateral, $\pm 1.05-1.10 \mathrm{~mm}$; ventral, $8.1 \mathrm{~mm}$ from the cortical surface (Paxinos and Watson, 1998). Self-tapping stainless steel screws were placed in the skull plates over the cerebellar cortex, parietal cortex, and frontal cortex, and dental cement anchored the electrode assembly in place. All procedures were conducted according to an institutionally approved animal care protocol. All surgical procedures were conducted under sterile conditions, and the rats were allowed a 1 week postoperative recovery before single unit screening commenced.

Isolation and recording of single unit activity. After recovery from surgery, the activity from each microelectrode wire was assessed during daily unit screening sessions while the rat foraged for food pellets in the cylinder. The electrode wires were advanced over several weeks while screening for single-unit waveforms that were of an acceptable amplitude for isolation from background electrical noise. Each rat was transported into the screening area from the animal colony room in a covered corrugated cardboard enclosure $(\sim 30 \times 30 \mathrm{~cm}$ box $)$. The cardboard box was placed on the floor inside the curtained enclosure next to the cylinder. A recording cable was attached to the implanted electrode while the rat was held gently in a towel. The rat was then released into the cylinder apparatus from a start position that varied daily in a pseudorandom manner. Unit activity was recorded using procedures similar to those described previously (Taube et al., 1990a; Taube, 1995). Briefly, electrical signals were passed through a field-effect transistor (FET) (1 FET/electrode) in a source-follower configuration through an overhead commutator (Biela Development), amplified (Grass Instruments, P5 Series), bandpass filtered $(300-10,000 \mathrm{~Hz}, 3 \mathrm{~dB} /$ octave; Peavey Electronics, model PME8), and then through a series of window discriminators (BAK Electronics, model DDIS-1). The resultant signal was then displayed on an oscilloscope (Tektronix, model 2214). Electrode activity was monitored while observing the rat's behavior on a video monitor with a camera mounted $3 \mathrm{~m}$ above the cylinder floor. If well isolated cells were not found, the electrodes were advanced $25-50 \mu \mathrm{m}$ further into the brain, and the activity was monitored on the electrodes again the next day. Screening for cells occurred over the course of several weeks.

When the waveform of a single cell could be sufficiently isolated from the background electrical noise, two light-emitting diodes (LEDs) (a red LED positioned over the rat's snout, and a green LED positioned over its back) were added to the recording cable. The $x, y$ coordinates of the LEDs were monitored at $60 \mathrm{~Hz}$ by a video-tracking system (Eberle Electronics). During 8 min recording sessions the LED coordinates and the neuronal discharges were sampled at $60 \mathrm{~Hz}$ and acquired by a data acquisition interface board (National Instruments, model DIO-96) in a personal computer (Macintosh Quadra 840AV). Data were stored for subsequent off-line analyses using LabView software programs (National Instruments). The rat's location was defined as the point $25 \%$ of the distance from the red LED along the line between the two LEDs; this point corresponded to the position of the rat's head. During recording sessions, a speaker mounted on the ceiling and centered above the cylinder broadcast white noise to mask any uncontrolled auditory cues.

Data analysis. The rat's head direction was determined from the relative positions of the two LEDs using procedures defined previously (Taube et al., 1990a; Taube, 1995). Consistent with these studies, the HD by firing rate tuning curve functions were considered as triangles, and each HD cell was analyzed to determine the basic firing properties: (1) preferred firing direction; (2) peak firing rate; (3) directional firing range; (4) asymmetry ratio; (5) mean background firing rate; and (6) overall mean firing rate independent of HD. The triangular analysis of the results of each HD cell provides left and right triangular legs of the firing rate by HD tuning function. The slopes of the best-fit lines through the left and right triangular legs were determined, and an asymmetry ratio was calculated by comparing the left leg slope to the absolute value of the right leg slope. An asymmetry ratio of 1 indicates that the slopes of the left and right legs are symmetrical.

For the present results we also computed the directional information content value for each HD cell. Information content per spike represents a quantitative measure of the amount of information that is conveyed by each spike generated by a cell (Skaggs et al., 1993). In this case, the directional information content can be thought of as a measure of the degree to which cell firing can predict the animal's directional heading. The information content for HD cells was calculated using the following formula:

\section{$\Sigma p_{i}\left(\lambda_{i} / \lambda\right) \log _{2}\left(\lambda_{i} / \lambda\right)$}

where $p_{i}=$ probability that the head pointed in the $i$ th bin $\left(p_{i}\right.$ is the dwell time of the head in the $i$ th bin divided by the total recording time); $\lambda_{i}=$ the mean firing rate of the cell in the $i$ th bin of HD; and $\lambda=$ the overall mean firing rate of the cell for the entire recording session. A directional information content value of 0 reflects no correlation between directional heading and the firing of the cell; a value approaching or $>1$ indicates a strong positive correlation between directional heading and firing rate.

Linear velocity. Analytical procedures described previously (Taube, 1995) were used to evaluate the dependence of LMN HD cell-firing rates on linear velocity. For each HD cell, all episodes of at least 10 consecutive samples $(0.167 \mathrm{sec})$ in which the rat maintained its head direction within the preferred firing direction of the cell $\left( \pm 6^{\circ}\right.$ arc $)$ were selected from each $8 \mathrm{~min}$ recording session. Cells were excluded if $<10$ episodes occurred within the recording session. For each episode the distance the rat traveled between the first and last samples was correlated with the mean firing rate across the episode.

Angular velocity. Angular head velocity was determined using methods described previously (Taube, 1995). Briefly, for each cell, samples were selected from the $8 \mathrm{~min}$ recording session during which the rat pointed its head within $\pm 6^{\circ}$ of the preferred firing direction. For each sample $(n)$, angular head velocity was determined by taking the first derivative of the $\mathrm{HD}$ versus time function. However, before taking the first derivative, we first "smoothed" the HD versus time function to reduce the error caused by video interlacing. The HD versus time function was smoothed using the function: $\left[n=\left(n_{t-2}+n_{t-1}+n+n_{t+1}+n_{t+2} / 5\right]\right.$. Next, the first derivative for each sample was calculated by defining an episode of five time points centered on that sample and then determining the slope of the best-fit line through those five points. Clockwise (CW) turns were 
indicated by negative slopes, whereas counterclockwise (CCW) turns were indicated by positive slopes. The absolute value of angular head velocity for each time point was compared with the firing rate associated with that episode (number of spikes in the episode divided by episode duration) and a correlation value determined across all samples $\left(r_{\text {av }}\right)$. In addition to this overall correlation, we also calculated a correlation value based on $\mathrm{CW}$ and $\mathrm{CCW}$ head turns $\left(r_{\mathrm{cw}}\right.$ and $\left.r_{\mathrm{ccw}}\right)$.

A similar approach was used to examine the influence of angular head velocity on the firing rates of nondirectional LMN single units. For these cells (head pitch cells and AHV cells), we modified the analysis to include all directional headings of the rat. For each cell, the mean firing rates were determined for specific angular head velocity intervals (in \%sec: 0-90, 90-180, 180-270, and 270-1000).

Optimal time shift. To determine the optimal temporal relationship between LMN HD cell firing and the rat's directional heading, we used two analytical methods. The first method used was a time-shift procedure, the details of which have been described previously (Taube and Muller, 1998). This analysis involves shifting the spike time series forward and backward in time in $1 / 60$ th sec intervals $(16.6 \mathrm{msec})$, relative to the head direction time series. For each $1 / 60$ th sec time shift, a firing rate versus HD function is determined, and three HD cell properties are measured: peak firing rate, directional range width, and directional information content. For the following analyses, the range width is defined as the width (in degrees) of the firing rate by HD function at 0.3 of the peak firing rate. The optimal time shift for each parameter is the amount the spike series is shifted that yields the maximum peak firing rate and information content, and minimal directional range width. A negative optimal time shift indicates that cell firing is associated with the rat's past $\mathrm{HD}$, whereas a positive optimal time shift indicates that cell firing is associated with the rat's future HD.

The second method used to investigate the temporal nature of HD cell activity examined the preferred firing directions exhibited during $\mathrm{CW}$ and CCW head turns (Blair and Sharp, 1995). To quantify this relationship, Blair and Sharp (1995) calculated the separation angle (d), or difference in degrees between the preferred firing directions for CCW and $\mathrm{CW}$ head turns, computed as $\partial=$ peak $(\mathrm{CCW})-$ peak $(\mathrm{CW})$. The preferred firing direction for this analysis was defined as the center of the weighted average of all the firing rates $\pm 90^{\circ}$ around the preferred direction for each $\mathrm{CW}$ and $\mathrm{CCW}$ function. A negative $\partial$ value indicates that cell firing lags current head direction, whereas a positive $\partial$ value indicates that cell firing leads or anticipates head direction.

Cue card rotation. To evaluate the stimulus control exerted by the cue card, some HD cells were recorded after a $90^{\circ}$ rotation of the cue card. The HD cell was first recorded during an 8 min recording session during which the cue card was affixed to the cylinder wall at the 3 o'clock position. Without disconnecting the rat from the recording equipment, the rat was removed from the cylinder to the cardboard enclosure. With the rat out of view, the cue card was rotated to a position on the cylinder wall $90^{\circ} \mathrm{CCW}$, and the floor paper was replaced. The rat was gently disoriented in the cardboard enclosure for 1-2 min by the experimenter walking around the cylinder while turning the box slowly. The rat was then returned to the cylinder at an entry point different from that of the initial recording session. The cell was recorded for a second $8 \mathrm{~min}$ session. After completion of this "rotation" session, the rat was again returned to the cardboard enclosure, and the above procedures were repeated. The cue card was returned to the standard position (i.e., 3 o'clock), and a final 8 min session was recorded.

To quantify the deviation of the preferred direction shift from the expected $90^{\circ}$ shift, we used a cross-correlation method described in detail previously (Taube et al., 1990a). The firing rate versus HD tuning function of the rotation session was shifted in $6^{\circ}$ increments and crosscorrelated with the tuning function of the same cell recorded during the initial standard session. The degree of shift necessary to maximize the correlation between the tuning functions of the two recording sessions was considered the rotation of the preferred firing direction. This analysis was also used to determine the consistency of the preferred firing direction between the initial and final standard sessions.

At the conclusion of these analyses, the electrode array was advanced further through the brain over the course of several months, and additional unit activity was screened for spatial correlates. Unit screening was terminated when the electrode array had been advanced $\sim 2 \mathrm{~mm}$.

Head pitch cell analysis. Pitch of the animal's head was assessed by plotting firing rate by head pitch. Head pitch was calculated for each 60 $\mathrm{Hz}$ sample by computing the distance between the red and green LEDs that were fixed to the recording cable over the rat's snout and back, respectively. Because the video camera remained fixed at the ceiling, the distance between the two LEDs as viewed by the overhead camera is proportional to the cosine of the pitch of the rat's head. Note, however, that this method does not distinguish whether the rat's head is pitched up or down. For example, if the rat stood on all four feet, with the rat's head oriented parallel to the cylinder floor (head pitch $=0^{\circ}$ vertical), the apparent distance between the two LEDs was $11 \mathrm{~cm}$. The apparent distance between the LEDs approached $0 \mathrm{~cm}$ as the rat's head pitched toward $90^{\circ}$ vertical. However, if the rat reared but its head pitch was $0^{\circ}$, the apparent distance of the LEDs would be detected by the video tracking system as $>11.00 \mathrm{~cm}$, because the LEDs are closer to the camera. To correct for this problem, head pitch values were determined by dividing the distance value (in centimeters) of each sample by the overall maximal LED distance value and computing the arc cosine of the result. Head pitch values were expressed in degrees. For example, a head pitch of $+70^{\circ}$ vertical would be interpreted by the video tracking system as a red-to-green LED distance measure of $3.76 \mathrm{~cm}$, assuming an overall maximal distance value of $11.00 \mathrm{~cm}$. The maximum vertical pitch that was reliably detected by the video tracking system was $+82^{\circ}$ vertical. Note that this method of calculating head pitch is unable to distinguish between episodes when the rat's head was pitched toward the ceiling and when pitched toward the cylinder floor. However, preliminary tests determined the range of LED distances likely to occur when the rat's head was pitched toward the floor. These tests indicated that head pitch values $\leq 40^{\circ}$ were contaminated by both positive and negative head pitch events. More importantly, head pitch values $\geq 40^{\circ}$ occurred only when the rat's head was pointed upward toward the ceiling.

Firing rate by head pitch plots were generated for each head pitch cell using the following procedure. For each $1 / 60$ th sec sample, the rat's head pitch was determined by dividing the red-to-green LED distance as viewed by the video camera by the overall maximal LED distance value. The resulting value was assigned to one of 23 bins (bin $1=$ maximum distance; bin $23=$ minimum distance) along with the number of spikes discharged during that sample. The total time and the number of spikes at each head pitch bin were computed. Firing rates for each bin were then determined by dividing the number of spikes by the sampling time in each bin. Samples were excluded from analysis in the event of nondetection of either LED, or if the red-to-green LED distance exceeded 13.00 $\mathrm{cm}$. During our preliminary tests of the resolution of head pitch we never encountered an LED distance measure $>13.00 \mathrm{~cm}$ even while the rat was rearing, thus any distance measure $>13.00 \mathrm{~cm}$ reflects an erroneous measure. Respective distance values corresponding to each bin were translated to degrees of pitch by taking the arc cosine of the distance value. Pitch bin 1 corresponded to head pitch values between 0 and $4^{\circ}$; pitch bin 2 corresponded to head pitch values between 4 and $8^{\circ} ; \ldots$ and pitch bin 23 corresponded to head pitch values between 88 and $90^{\circ}$. The resulting cell discharge rates were plotted as a function of head pitch to assess tuning of the LMN head pitch cells. Because we never observed any sampling of head pitch $>84^{\circ}$, for graphical purposes we combined all firing rate values for head pitch samples $\geq 80^{\circ}$. Thus, the head pitchtuning functions depict the representative firing rates for head pitch from 0 to $\geq 80^{\circ}$. To collect a sufficient number of different head pitch samples, all head pitch cells were recorded for $16 \mathrm{~min}$.

Statistical procedures. ANOVA and $t$ tests were used to evaluate the relationship between LMN cell activity and a number of factors (i.e., linear and angular velocity, temporal relationship of HD to cell activity, and cue rotation). A criterion level of $p<0.05$ was used for all statistical analyses. Potential differences between the firing properties of LMN cells and those of PoS and ADN were statistically evaluated using one- or two-factor ANOVAs, followed by post hoc Scheffé multiple comparisons tests when appropriate.

Histology. At the conclusion of unit screening, rats were overdosed with sodium pentobarbital (100 mg/kg; i.p.). Weak anodal current (15 $\mu \mathrm{A}$ for $10 \mathrm{sec}$ ) was passed through one of the electrode wires to mark its location by the deposition of iron (Prussian blue reaction). The rats were perfused transcardially with $0.9 \%$ saline followed by $10 \%$ formalin, and the brains were removed and placed into $10 \%$ formalin for at least $48 \mathrm{hr}$. The brains were then transferred to a $10 \%$ formalin solution containing $2 \%$ potassium ferrocyanide for $24 \mathrm{hr}$ and returned to a $10 \%$ formalin solution for $24 \mathrm{hr}$, after which the brains were placed into a $20 \%$ sucrose solution for at least $48 \mathrm{hr}$. The brains were then blocked, frozen on dry ice, sectioned coronally at $25 \mu \mathrm{m}$ on a cryostat, and mounted on to microscope slides. The sections were stained with cresyl violet and examined under light microscopy to determine the location of recording sites. 


\section{RESULTS}

\section{Histology}

Histological analyses after completion of unit screening verified that each electrode array had passed through the LMN in all 17 rats. Recording electrode tracks were identified by the Prussian blue reaction at the ventral most limit of the lateral mammillary nuclei or immediately ventral to it. Given the proximity of the LMN to the ventral surface of the brain, in some cases it was difficult to localize a Prussian blue reaction despite the more obvious presence of the electrode cannula track through the tissue. Indeed, in a few cases the Prussian blue reaction could not be observed because the electrode wires had advanced through the ventral surface of the brain. Moreover, because only one wire from each electrode was identified by the Prussian blue reaction, it is possible that some of the electrode wires passed through the lateral extent of the medial mammillary nucleus or lateral to the LMN. Figure 1 shows a photograph of a cresyl violet-stained coronal section from one rat depicting the recording site. The photograph represents a high magnification view of the area indicated on the coronal schematic by the dashed line box. In this case, the electrode was directed at the right LMN, and the arrow points to the track of the electrode passing through the LMN. Based on our histological assessment of the electrode tracks from all rats, we believe that most, if not all of the cells discussed below were localized to the LMN.

\section{Qualitative description of cell sample}

A total of 87 cells were recorded from 17 rats. Twenty LMN single units $(23 \%)$ were identified as head direction cells. Qualitatively, the firing characteristics of LMN HD cells appeared similar to HD cells recorded from the PoS and ADN. LMN HD cells discharged as a function of the rat's directional heading in the horizontal, or yaw plane, with each cell discharging maximally at only one preferred firing direction. The preferred firing directions of all LMN HD cells were uniformly distributed over the $360^{\circ}$ range, and the preferred direction of each cell remained stable throughout the recording session. Therefore, all vectors representing the rat's head direction at the time of peak cell discharge were parallel. Qualitative assessment determined that with the rat's head oriented in the preferred firing direction of the cell, head pitch (rotation of the head up or down) up to $90^{\circ}$ vertical, head roll (rotation around the anteroposterior axis), or rearing of the rat, did not alter cell firing significantly. Consistent with HD cells recorded from the ADN and PoS, the firing of LMN HD cells was independent of the rat's location within the cylinder or its ongoing behaviors (e.g., chewing, grooming, sniffing, running, walking, or motionless; no HD cells were monitored during sleep).

The remainder of the recorded units were identified as nondirectional cells. Each cell that exhibited a waveform of sufficient amplitude was recorded for at least one 8 min recording session regardless of the classification of the cell. Of the 67 nondirectional cells recorded, (1) 14 cells (16\%) were classified as head pitch cells and discharged maximally whenever the rat pitched its head to near vertical; (2) 38 cells $(43.7 \%)$ were classified as angular head velocity (AHV) cells and exhibited firing rates that were modulated by the angular head velocity of the rat; (3) 11 cells $(12.6 \%)$ were classified as having nondeterminable correlates and exhibited a continuous high firing rate (30-40 spikes/sec) regardless of the rat's head direction, head pitch, location, or ongoing behavior; and (4) four cells $(4.6 \%)$ were classified as theta cells (Ranck, 1973) because these cells exhibited rhythmic firing pat- terns in the range of the theta frequency $(5-8 \mathrm{~Hz})$. Furthermore, the LMN theta cells discharged rhythmically during sniffing, eating, walking, and running behaviors. Although we did not concurrently record the rat's EEG, intracellular recording studies in vitro have shown that LMN neurons discharge rhythmically in theta frequency bursts (Llinas and Alonso, 1992). Furthermore, supramammillary neurons exhibit theta burst-firing patterns that are phasically locked to the hippocampal theta rhythm in anesthetized rats (Kocsis and Vertes, 1994) and in freely moving rats (McNaughton et al., 1995). Thus, it is likely that the "theta-like" cells that we recorded in the LMN are similar to theta cells observed in other parts of the limbic system.

Analyses revealed that there was no apparent topographical relationship between electrode placement and the spatial correlates recorded. In a number of cases HD cells were recorded and later after advancing the electrodes, AHV cells or head pitch cells were recorded from the same electrode wires. In a few instances, HD cells and AHV cells were recorded simultaneously from distinct electrode wires.

\section{Quantitative analyses of LMN HD cell-firing properties}

The firing properties of LMN HD cells were markedly similar to those of PoS and ADN HD cells. The percentage of LMN cells classified as HD cells $(23 \%)$ is lower than that reported for the ADN (56\%; Taube, 1995) but similar to that reported for the PoS (25\%; Taube et al., 1990a). There were no significant differences in firing properties between HD cells recorded from the right $(n=14)$ and left $(n=6) \mathrm{LMN}$, and this data were therefore pooled into a single group. Figure 2 illustrates firing rate versus head direction plots for four LMN HD cells, each plot was recorded from a different rat. The plots illustrate that cell discharge was elevated above background firing rates over $\sim 170^{\circ}$, and there was a symmetrical decrease in firing rate away from the preferred direction. LMN cells were analyzed to determine the peak firing rate, preferred firing direction, directional firing range, directional information content, background firing rate, and signal-to-noise ratio. To determine potential regional differences in HD cell populations, the data from these LMN cells were compared with a population of HD cells in the PoS $(n=25)$ and $\operatorname{ADN}(n=29)$ that were recorded under identical conditions (Table 1).

\section{Peak firing rates}

LMN HD cells exhibited a mean \pm SEM observed peak firing rate of $69.53 \pm 13.67 \mathrm{spikes} / \mathrm{sec}$. Although the peak firing rate for a given HD cell was consistent across recording sessions, there was considerable variability in peak firing rates across the population of cells (range, 9.75-226.46). Figure $3 A$ represents a frequency distribution of the peak firing rates. When multiple HD cells were recorded from the same rat, each cell exhibited a distinct peak firing rate, and there was no trend for HD cells recorded from the same animal to exhibit similar peak firing rates.

Comparing LMN peak firing rate values with those from PoS and ADN HD cells (Table 1), a one-factor ANOVA yielded a significant effect of region (PoS, ADN, LMN) $\left(F_{(2,67)}=9.77 ; p<\right.$ 0.002). Post hoc Scheffé multiple comparisons tests indicated that the observed peak firing rates of LMN HD cells were significantly higher than those of PoS and ADN HD cells. Consistent with data from Taube (1995), there were no significant differences in peak firing rates between ADN and PoS HD cells. 

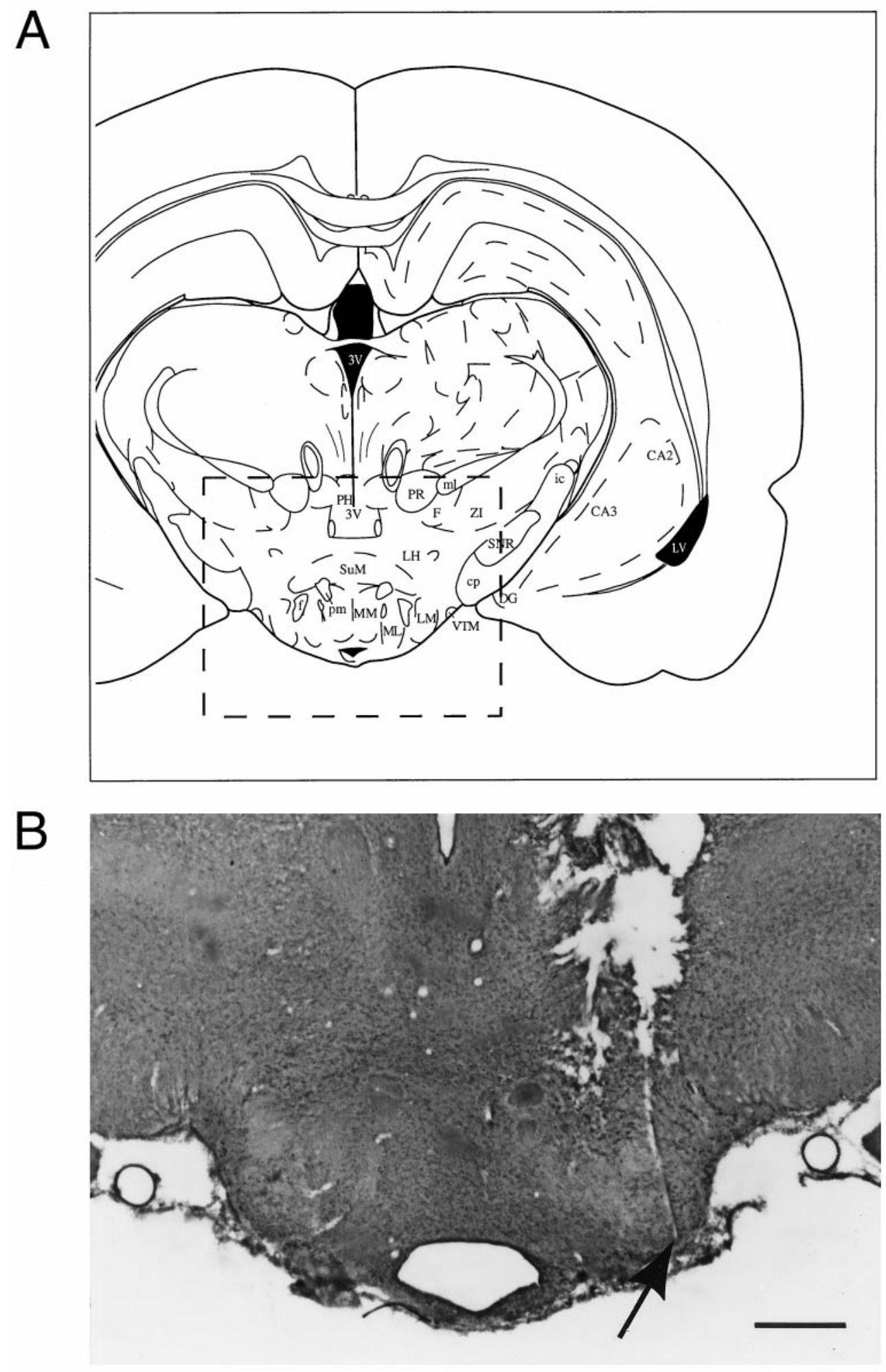

Figure 1. Representative recording site. $A$, Schematic diagram of a coronal section at the level of the $\mathrm{LMN}$ at -4.52 $\mathrm{mm}$ from bregma, modified from the atlas of Paxinos and Watson (1998). The dashed box depicts the outline of the region from which the photomicrograph $(B)$ was taken. $B$, Photomicrograph of a coronal section stained for cresyl violet illustrating the electrode track passing through the LMN. Arrow indicates the ventral tip of the electrode track. $3 \mathrm{~V}$, Third ventricle; $C A 2-3, \mathrm{CA} 2, \mathrm{CA} 3$ of hippocampus; $c p$, cerebral peduncle; $D G$, dentate gyrus; $F$, nucleus of fields of Forel; $f$, fornix; ic, internal capsule; $L H$, lateral hypothalamus; $L M$, lateral mammillary nuclei; $L V$, lateral ventricle; $M M$, medial mammillary nuclei; $M L$, lateral aspect of medial mammillary nuclei; $m l$, medial lemniscus; $p m$, premammillary tract; $P H$, posterior hypothalamus; $P R$, prerubral field; SNR, substantia nigra pars reticulata; SuM, supramammillary nuclei; $V T M$, ventral tuberomammillary nuclei; $Z I$, zona incerta. Scale bar, $0.5 \mathrm{~mm}$

\section{Preferred firing directions}

In general, the preferred firing directions of LMN HD cells were uniformly distributed around $360^{\circ}$; only one HD cell exhibited a preferred firing direction between 180 and $225^{\circ}$, whereas four cells exhibited preferred directions between 315 and $360^{\circ}$. The results of a Rayleigh test (Batschelet, 1981) indicated that this sample was randomly distributed around $360^{\circ}, r(20)=0.18 ; p>$
0.53. The frequency distribution of preferred firing directions of LMN HD cells is depicted in Figure $3 B$.

\section{Directional firing range}

The mean directional firing range of LMN HD cells was $168.16 \pm 8.04^{\circ}\left(\right.$ range, $\left.81.01-220.07^{\circ}\right)$. A frequency distribution of directional firing ranges is presented in Figure $3 C$. The direc- 

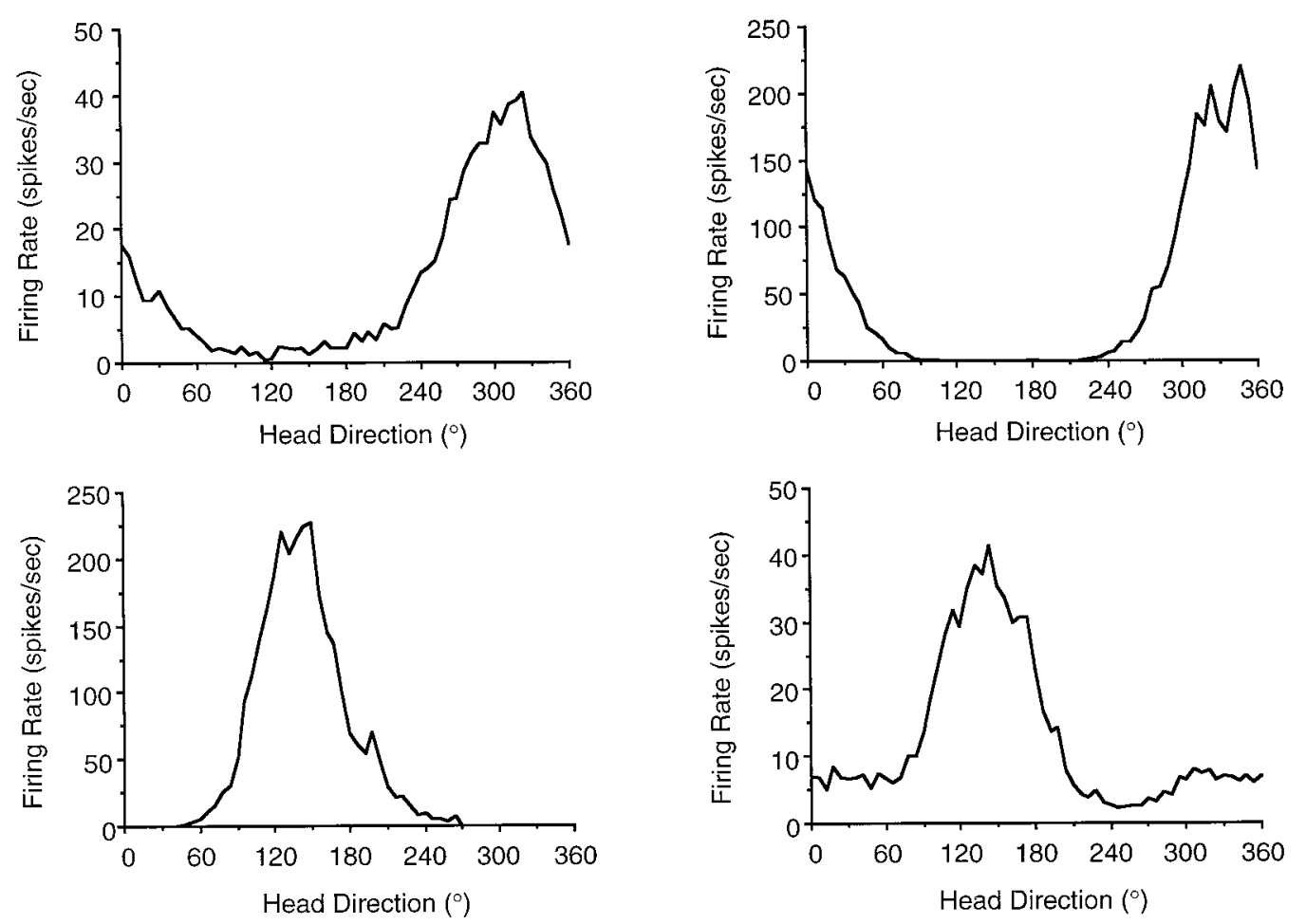

Figure 2. Plots of firing rate as a function of head direction for four representative HD cells recorded in the LMN of four different rats. Plots were generated from data collected in $6^{\circ}$ bins during 8 min recording sessions. These plots illustrate the different types of peak firing rates, directional range widths, and background firing rates found across LMN HD cells. Each cell exhibited a distinct preferred firing direction. The cell depicted in the bottom right was recorded from the left LMN, whereas the remaining three cells depicted were recorded from the right LMN.

Table 1. Regional comparison of head direction cell-firing properties

\begin{tabular}{|c|c|c|c|c|c|c|}
\hline \multirow[b]{2}{*}{ Measure } & \multicolumn{2}{|c|}{ Lateral mammillary $(n=20)$} & \multicolumn{2}{|c|}{ Anterior thalamic $(n=29)$} & \multicolumn{2}{|c|}{ Postsubicular $(n=21)$} \\
\hline & Mean & Range & Mean & Range & Mean & Range \\
\hline Observed peak firing rate & $69.53 \pm 13.67^{*, * *}$ & $9.75-226.46$ & $36.91 \pm 4.13$ & $8.20-84.21$ & $20.52 \pm 2.60$ & $4.72-54.92$ \\
\hline Directional firing range & $168.16 \pm 8.04^{*, * *}$ & $81.01-220.07$ & $106.62 \pm 2.71$ & $78.80-133.04$ & $100.12 \pm 7.77$ & $59.82-204.84$ \\
\hline Information content & $0.81 \pm 0.13^{*}$ & $0.20-2.62$ & $1.24 \pm 0.09$ & $0.56-2.20$ & $1.10 \pm 0.13$ & $0.25-1.97$ \\
\hline Asymmetry ratio & $1.17 \pm 0.14$ & $0.66-3.30$ & $1.06 \pm 0.05$ & $0.49-1.43$ & $0.96 \pm 0.06$ & $0.39-1.50$ \\
\hline Background firing rate & $5.11 \pm 1.78^{*, * *}$ & $0.03-35.49$ & $1.78 \pm 0.37$ & $0.10-8.24$ & $1.38 \pm 0.31$ & $0.04-5.50$ \\
\hline Signal-to-noise ratio & $56.51 \pm 21.09$ & $3.27-354.64$ & $62.94 \pm 17.60$ & $5.37-402.11$ & $36.37 \pm 8.41$ & $4.42-149.02$ \\
\hline Linear velocity $r$ & $0.24 \pm 0.04$ & $0.005-0.60$ & $0.22 \pm 0.02$ & $0.26-0.50$ & $0.20 \pm 0.04$ & $0.0004-0.70$ \\
\hline Angular velocity $r$ & $0.08 \pm 0.03^{* *}$ & $-0.16-0.30$ & $0.05 \pm 0.009^{* *}$ & $-0.02-0.18$ & $-0.02 \pm 0.02$ & $-0.17-0.22$ \\
\hline
\end{tabular}

${ }^{*} p<0.05$ versus ATN, ${ }^{* *} p<0.05$ versus PoS, post hoc Scheffé multiple comparisons analyses.

tional firing ranges of LMN HD cells were significantly larger than the ranges observed in PoS and ADN HD cells (Table 1) (one-factor ANOVA, $F_{(2,67)}=35.7 ; p<0.0002$ ). In agreement with a previous study, there was no significant difference between PoS and ADN HD cells (Taube, 1995). Previous analyses have demonstrated a weak correlation between the peak firing rate and directional firing range of HD cells recorded from $\operatorname{PoS}(r=0.52$; Taube et al., 1990a) and ADN ( $r=0.18$; Taube, 1995). For LMN HD cells, the correlation between these two parameters was also weak, $r=0.18$.

\section{Directional information content}

A frequency distribution of directional information content values for LMN HD cells is presented in Figure 3D. The mean directional information content was $0.81 \pm 0.13^{\circ}$ (range, $0.20-$ 2.62). A one-factor ANOVA yielded a significant effect of region
$\left(F_{(2,67)}=3.74 ; p<0.03\right)$ when comparing the mean directional information content across the LMN, PoS, and ADN (Table 1). Post hoc Scheffé multiple comparisons tests indicated that the mean directional information content of LMN HD cells was significantly lower than that of ADN HD cells but not significantly different from that of PoS HD cells. Directional information content values for PoS HD cells were not significantly different from that of ADN HD cells.

\section{Asymmetry of the firing rate by head direction-tuning function}

The mean asymmetry ratio for LMN HD cells was $1.17 \pm 0.14$ (range, 0.66-3.30), demonstrating a near symmetrical decrease in firing rates in both directions away from the preferred firing direction. The asymmetry ratio values of LMN HD cells compared with PoS and ADN HD cells are shown in Table 1. There 

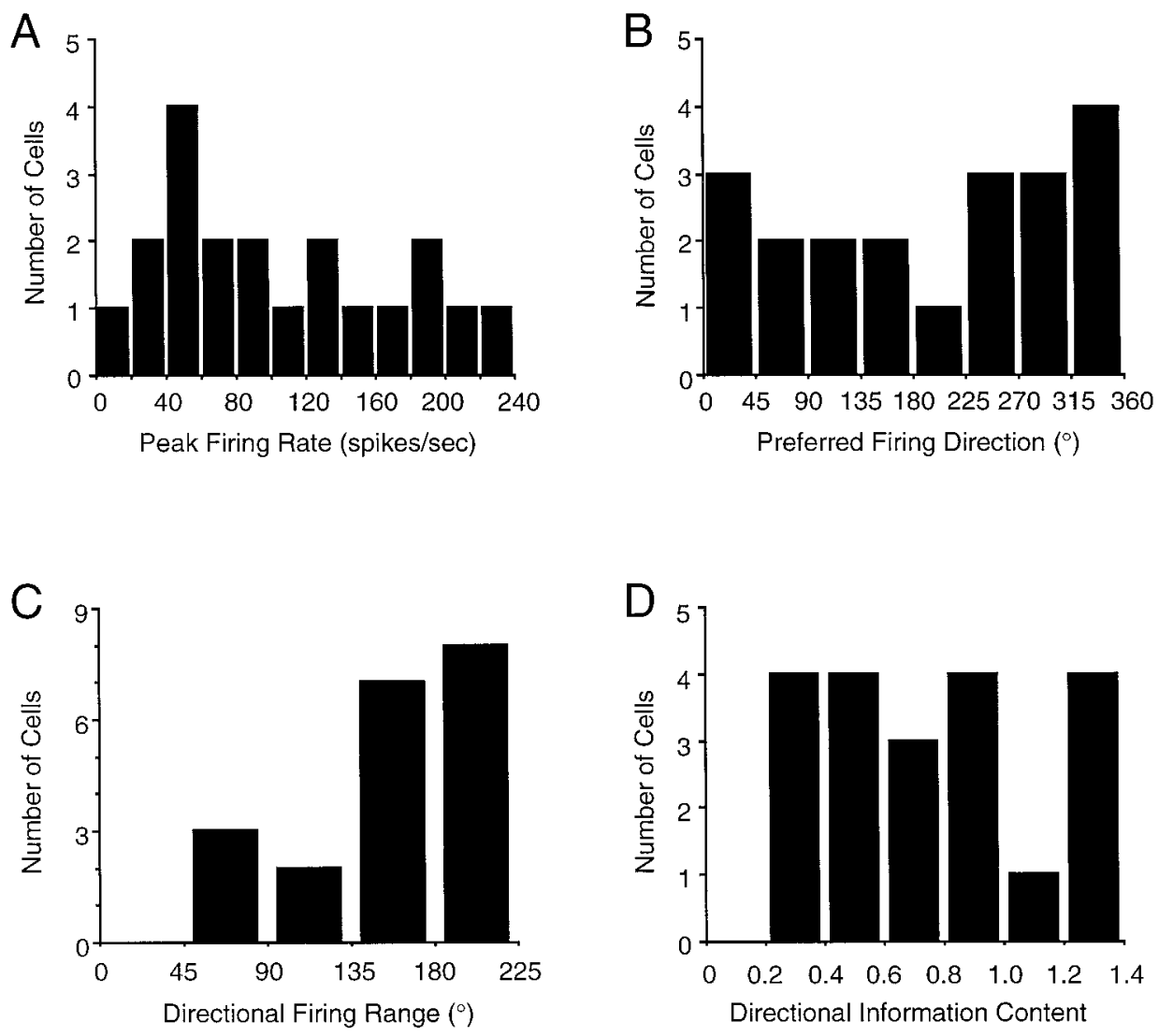

Figure 3. Frequency distribution histograms of peak firing rate $(A)$; preferred firing direction $(B)$; direction firing range $(C)$; and directional information content $(D)$ for all 20 LMN HD cells. See Results for details.

were no significant differences in asymmetry ratio values across the three brain regions $\left(F_{(2,67)}=1.62, \mathrm{NS}\right)$.

\section{Background firing rates and signal-to-noise ratio}

Background firing rates were generally low for most LMN HD cells, although 16 of 20 cells had background firing rates above 1 spike/sec. The mean background firing rate was $5.11 \pm 1.78$ spikes/sec (range, 0.03-35.49 spikes/sec). All cells reported here were well isolated waveforms; therefore, it is unlikely that poor isolation contributed significantly to the observed higher background firing rates. LMN HD cells had higher background firing rates than PoS and $\mathrm{ADN}$ HD cells $\left(F_{(2,67)}=4.38 ; p<0.02\right)$. Background firing rates for PoS HD cells were not significantly different from that of ADN HD cells. The mean signal-to-noise ratio for LMN HD cells was $56.5 \pm 21.1$ (range, 3.3-354.6) and was not significantly different from PoS or ADN HD cells $\left(F_{(2,67)}\right.$ $=0.66, \mathrm{NS})$.

\section{Linear velocity modulates LMN HD cell-firing rates}

We evaluated the dependence of LMN HD activity on linear velocity because previous reports have indicated a small influence of linear motion on the firing rates of PoS and ADN HD cells (Taube et al., 1990a; Taube, 1995). All recording sessions from the $20 \mathrm{LMN} \mathrm{HD}$ cells had at least 10 episodes in which the rat's directional heading remained within $\pm 6^{\circ}$ of the preferred direction of the cell; the mean number of episodes per cell was $27.20 \pm$ 1.78 (range, 11-42). For these episodes, the mean correlation value $\left(r_{\mathrm{lv}}\right)$ between linear velocity and firing rate was $0.24 \pm 0.04$ (range, 0.005-0.60), and a $t$ test showed that this $r$ value was unlikely to have arisen from a population value of zero $(t(19)=$ 5.81; $p<0.0002)$. Similar analyses on the populations of PoS and
ADN cells (Table 1 ) and comparison with LMN cells indicated that there was no significant effect of region $\left(F_{(2,65)}=0.33, \mathrm{NS}\right)$.

\section{Influence of head-turning behavior on LMN cell-firing rates \\ Angular head velocity modulates LMN firing rates}

In addition to linear velocity, previous reports have indicated that the discharge of ADN HD cells, but not PoS HD cells, is modulated by angular head velocity when firing rate increases with faster head turns through the preferred firing direction (Taube, 1995; Blair and Sharp, 1995; Taube and Muller, 1998). To determine whether LMN HD cells were also modulated by angular head velocity we first determined an overall correlation value $\left(r_{\text {av }}\right)$ for each cell, independent of turning direction. For the pooled sample of all $20 \mathrm{LMN} \mathrm{HD}$ cells, the mean $r_{\text {av }}$ value was $0.08 \pm 0.03$ (range, $-0.16-0.30$ ). Although this mean correlation is small, a $t$ test indicated that this mean value was unlikely to have arisen from a population with an expected mean of zero $[t(19)=2.59 ; p<0.02]$. These data demonstrate that increases in angular head velocity were found to be associated with higher LMN firing rates. Similar analyses were conducted on the populations of PoS and ADN HD cells, and the results were consistent with those obtained in previous studies (Table 1) (Taube, 1995; Blair and Sharp, 1995; Taube and Muller, 1998). Comparison of $r_{\text {av }}$ across the three brain regions revealed a significant effect of region $\left(F_{(2,67)}=7.22 ; p<0.0016\right)$, with post hoc tests indicating a significant difference between PoS HD cells and both LMN and ADN HD cells; there was no significant difference between ADN and LMN HD cells.

To assess whether the angular velocity-dependent modulation of LMN HD cell-firing rates was specific to preferred firing 
direction or a more general influence over the discharge of LMN neurons, we also assessed the influence of angular velocity on cell discharge when the rat's head was pointed $180^{\circ}$ ( $\pm 18^{\circ}$ of arc) away from the respective preferred firing direction. Specifically, is the background firing rate of LMN HD cells also modulated by angular velocity? The data from two LMN HD cells were not used because of insufficient sampling. The mean out-of-range $r_{\mathrm{av}}$ value was $0.06 \pm 0.02$ (range, -0.10 to 0.17 ), and was significantly different from a population with an expected mean of zero $(t(17)$ $=3.76 ; p<0.002)$. These data indicate that angular velocity also modulated the background firing rate of LMN HD cells, with higher firing rates associated with faster head turns. Similar analyses for ADN and PoS HD cells did not show this effect [ADN: mean out-of-range $r_{\mathrm{av}}=0.02 \pm 0.02, t(27)=1.39$, NS; PoS: mean out-of-range $r_{\mathrm{av}}=-0.01 \pm 0.01, t(20)=-0.92$, NS]. Therefore, the effect of angular velocity on the background firing rate may be unique to LMN HD cells. Taken together, these data indicate that angular head velocity has a more fundamental influence over LMN HD cell firing than for ADN HD cells, which were only modulated within the directional firing range of the cell, and for PoS HD cells, which were not modulated by angular head velocity at any directional heading.

\section{Influences of head-turning direction on firing rates of LMN HD cells}

Previous reports have shown that PoS and ADN HD cell firing is independent of the direction the head is turning (i.e., $\mathrm{CW}$ vs CCW) (Taube et al., 1990a; Taube, 1995; Blair and Sharp, 1995; Blair et al., 1997). In contrast, the peak firing rates of LMN HD cells appeared to be influenced by the direction of head turning, where the peak firing rate of the cell was higher for one turning direction compared with the other turning direction. Furthermore, this modulation was influenced by the side of the brain from which the cell was recorded. HD cells on the right side had higher peak firing rates for $\mathrm{CW}$ head turns, and HD cells in the left side had higher peak firing rates for $\mathrm{CCW}$ head turns. Figure 4, $A$ and $B$, depicts examples from the LMN from each side of the brain. In addition to the peak firing rate differences, note that the $\mathrm{CW}$ and $\mathrm{CCW}$ functions are shifted with respect to each other. This shift is a consequence of the anticipatory nature of LMN HD cells; we will return to this issue in the following section.

To further investigate the influence of head-turning direction, for each $\mathrm{HD}$ cell a $\mathrm{CW}$ :CCW ratio was calculated, in which the $\mathrm{CW}$ peak firing rate was divided by the $\mathrm{CCW}$ peak firing rate. A $\mathrm{CW}$ :CCW ratio value $<1$ would indicate higher peak firing rates during $\mathrm{CCW}$ head turns, a ratio value equal to 1 would indicate equivalent peak firing rates for $\mathrm{CW}$ and $\mathrm{CCW}$ head turns, and a ratio value $>1$ would indicate higher peak firing rates during $\mathrm{CW}$ head turns. Of the $20 \mathrm{HD}$ cells recorded from the LMN, six cells were recorded from the left side, and 14 cells were recorded from the right side. The frequency distribution of $\mathrm{CW}$ :CCW ratios across both sides is illustrated in Figure $4 E$. This histogram shows that 9 of $14 \mathrm{HD}$ cells recorded from the right side exhibited $\mathrm{CW}: \mathrm{CCW}$ ratios $\geq 1.2$ and five of six left side HD cells had $\mathrm{CW}: \mathrm{CCW}$ ratios $\leq 0.8$. The mean $\mathrm{CW}: \mathrm{CCW}$ ratios for cells in the right and left sides were $1.30 \pm 0.10$ and $0.91 \pm 0.08$, respectively; these mean ratios were significantly different from each other $(t(18)=-2.45 ; p<0.015)$.

To examine whether these properties are unique to LMN HD cells, we also performed similar analyses for the populations of PoS and ADN HD cells. All the cells from both populations were recorded in the right hemisphere of the PoS and the right side of the ADN. The mean $\mathrm{CW}: \mathrm{CCW}$ ratio for the PoS HD cells was $0.90 \pm 0.06$ (range, $0.50-1.40$ ); whereas the mean ratio for the ADN HD cells was $1.06 \pm 0.04$ (range, 0.45-1.43). Neither $\mathrm{CW}$ :CCW ratio mean value was found to be significantly different from a population with a mean of $1(\mathrm{PoS}, t(20)=-1.74$, NS; ADN, $t(28)=1.56$, NS). A one-factor ANOVA on CW:CCW ratio values yielded a significant effect of region $\left(F_{(2,67)}=5.48\right.$; $p<0.007)$, and post hoc comparisons indicated that the mean $\mathrm{CW}$ :CCW ratio of LMN HD cells was significantly different from that of both PoS and ADN HD cells; there was no difference between the PoS and ADN. Figure 4, $C$ and $D$, illustrates the CW and $\mathrm{CCW}$ firing rate versus HD tuning functions for a PoS HD cell and an ADN HD cell, respectively. Figure $4 F$ depicts the frequency distributions of $\mathrm{CW}$ : CCW ratio values for PoS and ADN cells. Although the frequency distribution data for the population of ADN cells reveals that the majority of cells had no preference for higher firing rates for $\mathrm{CW}$ or $\mathrm{CCW}$, the distribution for PoS cells is skewed. Six PoS cells had CW:CCW ratios $\leq 0.6$; these cells exhibited firing rates that were higher during CCW head turns. Consistent with these data, Taube et al. (1990a) reported that two PoS HD cells exhibited differential firing rates as a function of head-turning direction. Given that the present population of PoS and ADN HD cells were all recorded from the right side of the brain, the possibility of laterality differences remains. Nonetheless, Blair and Sharp (1995) reported an absence of differences in the firing rates of ADN HD cells, recorded from the left and right sides, when comparing their $\mathrm{CW}$ and $\mathrm{CCW}$ tuning functions. Collectively, these data demonstrate that the firing rates of LMN HD cells are modulated by head-turning direction.

Given that the LMN projects to the ADN, which in turn has reciprocal connections with the PoS, it is noteworthy that turn direction modulation is not a characteristic of either ADN or PoS HD cells and suggests that there are distinct differences in the quality of the HD signal across these neural regions. Although Taube et al. (1990a) reported two HD cells in the PoS that discharged at higher firing rates as the head turned either $\mathrm{CW}$ or $\mathrm{CCW}$ toward the preferred direction, these two cells were a distinct minority because they were the only two cells of 61 recorded HD cells that were modulated by turning direction. It is also noteworthy that the differences in LMN HD cell-firing rates between cells recorded on the left and right sides of the brain are consistent with the turning direction biases in the brainstem vestibular nuclei firing rates. Specifically, Type I vestibular neurons exhibit an increase in firing rates for horizontal angular head acceleration to the ipsilateral side, as compared with the firing rates during horizontal angular head acceleration to the contralateral side. Thus, a Type I vestibular neuron on the right side of the brain discharges at a higher rate during $\mathrm{CW}$ head turns than CCW head turns, and a Type I vestibular neuron on the left side discharges at a higher rate during $\mathrm{CCW}$ turns than $\mathrm{CW}$ turns. Therefore, the differential rates during $\mathrm{CCW}$ and $\mathrm{CW}$ head turns would provide a direction of head-turning representation. Such a signal from the vestibular nuclei may be conveyed to the LMN via the dorsal tegmental nucleus directly, or indirectly through the nucleus prepositus (Liu et al., 1984).

A small number of head turn-modulated HD cells have been observed in the retrosplenial and medial prestriate cortices (Chen et al., 1994). However, the turn modulation observed for these cortical HD cells was markedly different from the turn modulation reported here for LMN HD cells. Whereas LMN HD cell discharge is modulated within the directional firing range of the 

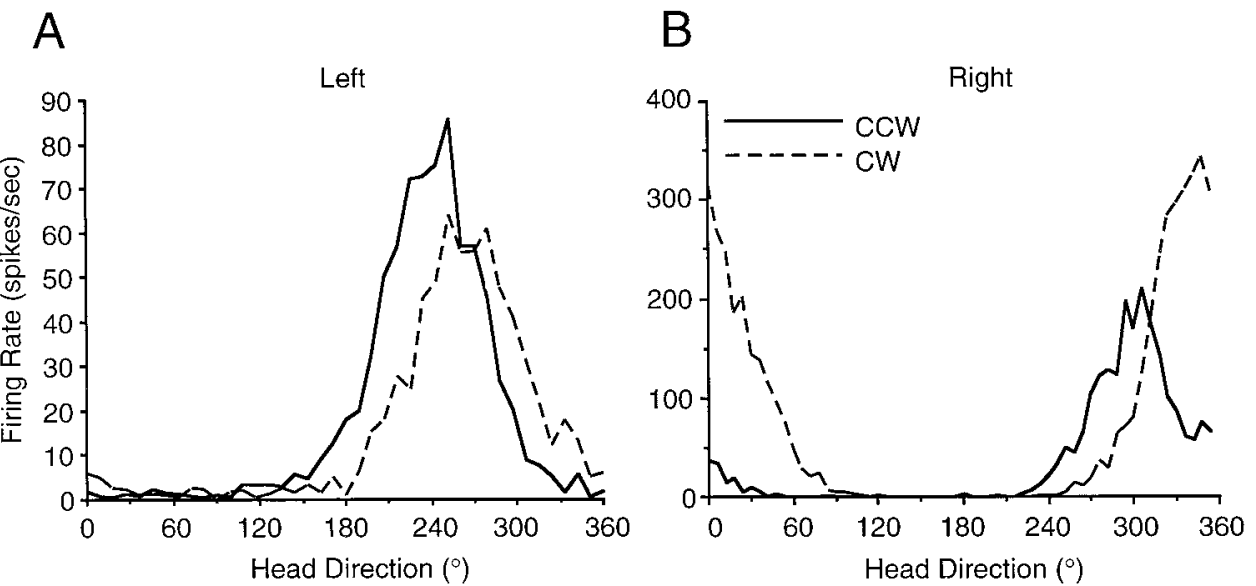

Figure 4. Differences in influence of turning direction on HD cells recorded from the left and right LMN. Most HD cells recorded from the left LMN exhibited higher firing rates during $\mathrm{CCW}$ head turns, whereas most HD cells recorded from the right LMN exhibited higher firing rates during $\mathrm{CW}$ head turns. $A, B$, Representative firing rate by HD-tuning curves during $\mathrm{CCW}$ and $\mathrm{CW}$ head turns for an LMN HD cell recorded from the left side $(A)$, and from the right side $(B)$. For each HD cell a $\mathrm{CW}$ :CCW ratio was calculated by dividing the $\mathrm{CW}$ peak firing rate by the CCW peak firing rate. $C, D$, Representative $\mathrm{CW}$ and $\mathrm{CCW}$ firing rate versus $H D$ tuning functions for a PoS HD cell $(C)$ and an ADN HD cell $(D)$. $E$, The frequency distribution of $\mathrm{CW}: \mathrm{CCW}$ ratios across both sides (open bars, left side; filled bars, right side) for LMN HD cells. $F$, The frequency distributions of $\mathrm{CW}$ : $\mathrm{CCW}$ ratios for PoS and ADN cells (open bars, $A D N$; filled bars, PoS). Note that the histogram for ADN cells reveals little preference for higher firing rates for $\mathrm{CW}$ or CCW turns, whereas the distribution for PoS cells indicates that six cells $(30 \%)$ exhibited higher firing rates for $\mathrm{CCW}$ turns than $\mathrm{CW}$ turns.
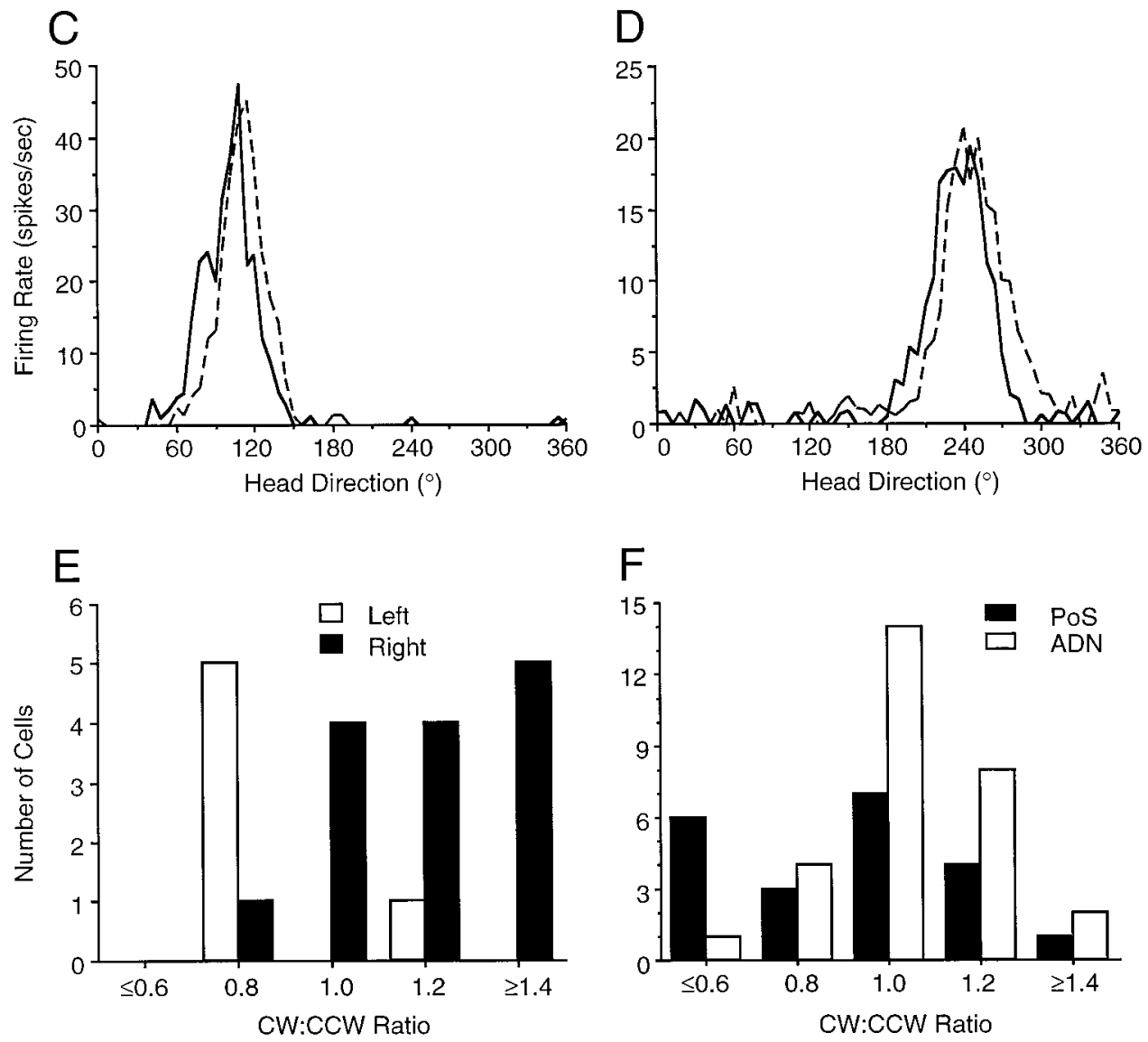

cell, HD cell discharge in these cortical areas was modulated over all directional headings (compare Fig. $4 A, B$ with Fig. $8 C$ of Chen et al., 1994). The head turn modulation of HD cell activity in these distinct brain areas suggests that LMN HD cells are head turn-modulated HD cells, whereas those in the cortical regions represent a dual code, signaling both head turn and directional heading.

\section{LMN HD cells exhibit anticipatory directional firing Optimal time shift analyses}

Previous studies have shown that the temporal relationship of cell firing to the rat's head direction differs across HD cells recorded from the PoS and ADN (Blair and Sharp, 1995, Blair et al., 1997, Taube and Muller, 1998). Specifically, HD cells in the ADN appear to encode the rat's future directional heading by $\sim 25$ msec, whereas HD cells in the PoS encode the rat's present or recent past directional heading. Of the $20 \mathrm{HD}$ cells recorded from the LMN, a second HD cell was recorded simultaneously on the same electrode wire for three cells. Because the tuning curves of these simultaneously recorded cells partially overlapped one another, the accuracy of the time shift analysis is likely to be compromised for these cells, and they were therefore excluded from the following analyses.

Time shift analyses were conducted on a representative session for each of the remaining $17 \mathrm{LMN}$ HD cells. Figure $5 A-C$ illustrates an example of the optimal time shifts of an LMN HD cell for each of the three parameters. For this cell, the optimal time shifts for peak firing rate, range width, and information 
A

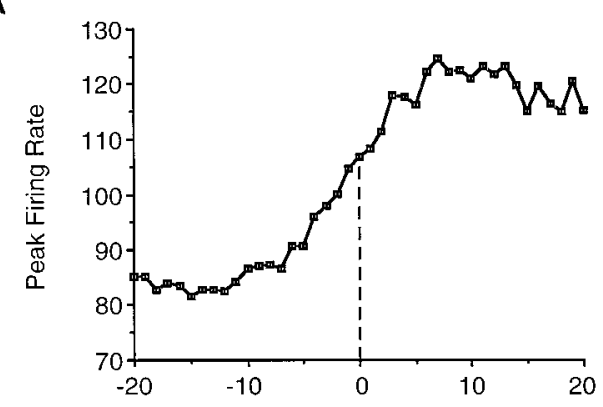

B

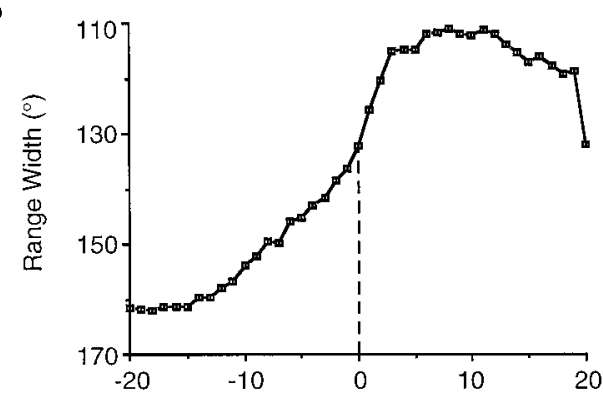

C

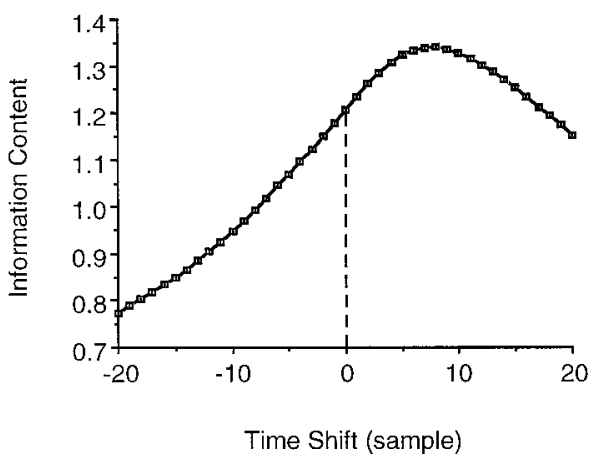

D

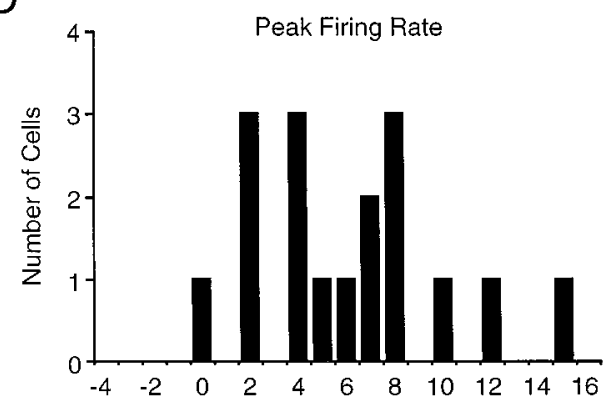

E

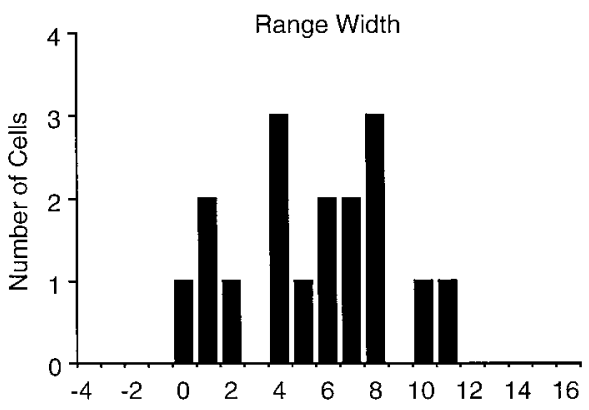

F $67 \quad$ Information Content

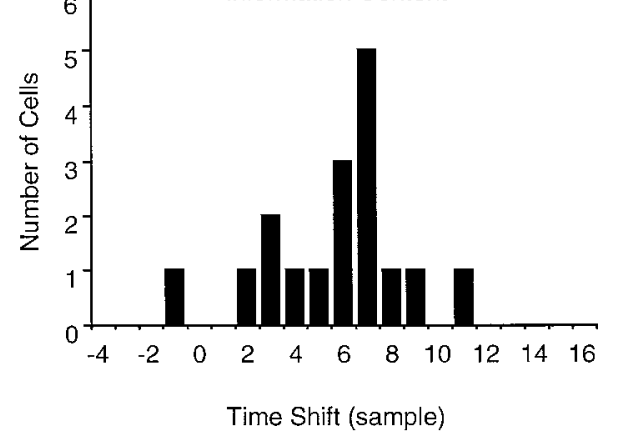

Figure 5. Parameter versus time shift plots for an LMN HD cell. $A$, Peak firing rate; $B$, range width; $C$, directional information content. The dashed line in each plot represents the zero time shift. Note that range width is plotted on a reversed $y$-axis with values decreasing away from the origin. Comparison of the optimal time shifts indicates that this cell exhibited a large positive optimal time shift (in samples) for each parameter: peak firing rate, +7 ; range width, +8 , information content, $+8 . D-F$, Frequency distribution histograms of different optimal time shifts of 17 LMN HD cells, for peak firing rate $(D)$, range width $(E)$, and information content $(F)$. The overall mean optimal time shift across all cells and parameters was 5.74 samples and indicates that the optimal firing of LMN HD cells anticipated the rat's directional heading by $95.8 \mathrm{msec}$.

content were $+7,+8$, and +8 samples, respectively. Note that range width is plotted on a reversed $y$-axis with values decreasing away from the origin. The mean optimal time shifts for LMN HD cells were: peak firing rate, +6.12 samples; range width, +5.41 samples; and directional information content, +5.71 samples. Therefore, the mean overall optimal time shift for LMN HD cells is +5.74 samples ( $95.8 \mathrm{msec}$ ) and is considerably larger than the $25 \mathrm{msec}$ value previously reported for ADN HD cells. The distributions of optimal time shifts for each measure are illustrated in Figure $5 D-F$. These plots indicate a considerable degree of variation in optimal time shift values, although it is apparent that the firing parameter measures are optimal at positive time shifts, indicating that the firing of LMN HD cells anticipates the rat's future head direction. For comparison, the optimal time shifts for the ADN and PoS HD cell populations are presented in Table 2. Consistent with previous reports, this sample of PoS HD cells exhibited an average optimal time shift near zero, whereas
ADN HD cells exhibited a positive optimal time shift. One-factor ANOVAs revealed significant regional differences in the optimal time shifts of all measures: maximum peak firing rate, $F_{(2,52)}=$ 28.07, $p<0.0002$; minimum directional range width, $F_{(2,52)}=$ 26.11, $p<0.0002$; maximum directional information content, $F_{(2,52)}=21.50, p<0.0002$. Post hoc tests indicated that the optimal time shift values of LMN cells were significantly greater than that of PoS and ADN cells for each of the three measures and that the optimal time shifts for ADN HD cells were significantly greater that of PoS HD cells.

To facilitate comparison of the optimal time shift values across neural regions, each parameter was normalized and plotted as a function of time shift interval. Every value was then normalized relative to the value corresponding to the optimal time shift. The resulting normalized data for all cells from a given region were then averaged. Finally, these averaged values were normalized again by the mean optimal value to produce mean normalized 


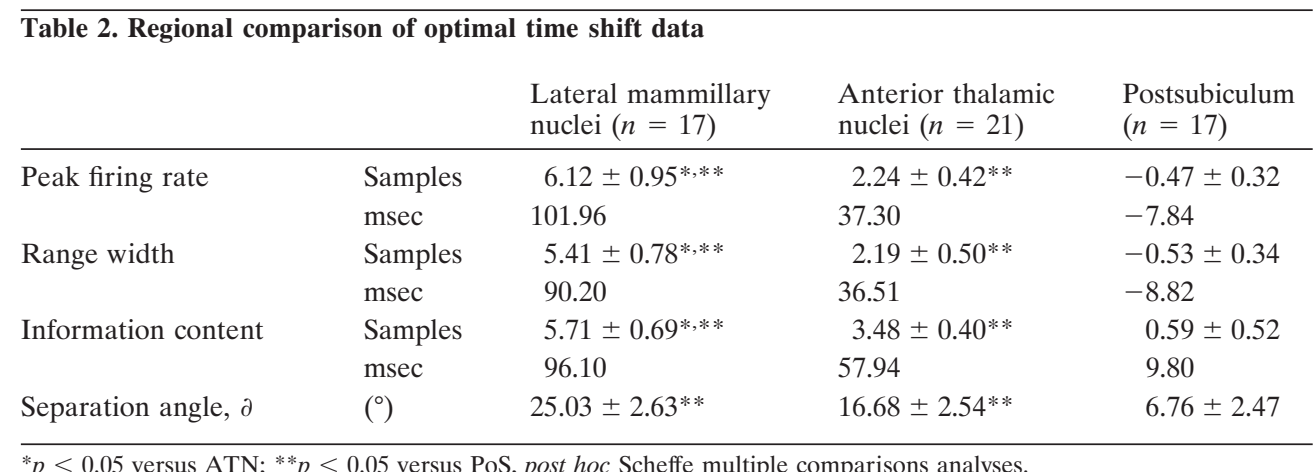

values for each time shift. With respect to the range width, the reciprocal values were computed before normalizing to simplify comparison of the range width data to that of peak firing rate and information content. The same analytical procedures were used to evaluate differences in the temporal relationship between PoS and ADN HD cell firing (Taube and Muller, 1998).

The mean normalized values for peak firing rate, reciprocal range width, and information content as a function of time shift interval for all LMN HD cells are depicted in Figure $6 A-C$. The time shift interval associated with the maximal value for each firing parameter measure is $+4,+5$, and +6 for peak firing rate, reciprocal range width, and information content, respectively, and is consistent with the optimal values determined from computing the means. The mean normalized plots for LMN HD cells are presented again in Figure $6 D-F$, together with the mean normalized data for each firing parameter for PoS and ADN HD cells. Across all three firing parameters, these plots illustrate that the degree of time shift necessary to produce the optimal firing value is greatest for LMN HD cells, followed by ADN HD cells. The marked differences in the anticipatory nature of HD cells across the PoS, ADN, and LMN are an intriguing finding. It is possible that the increased optimal time shift of LMN HD cells reflects a coarser coding of directional heading. Our data demonstrating the broader directional tuning of LMN cells as compared with those from ADN and PoS and the fact that LMN HD cell discharge rates are altered by multiple influences (speed and direction of head turning) are consistent with this view. However, it is also possible that the broader directional firing range is simply a consequence of the greater optimal time shift. In accordance with this view, we have found that across all three brain regions (PoS, ATN, and $\mathrm{LMN}$ ), there is a strong positive correlation between the directional firing range of an HD cell and its optimal time shift value, $r=0.59$. In sum, these results indicate that cell firing for both LMN and ADN HD cells anticipates the animal's future directional heading and that LMN HD cell firing anticipates the animal's directional heading by a larger amount than ADN HD cells (95 compared with $25 \mathrm{msec}$ ).

\section{Distinct preferred directions during $C C W$ and $C W$ head turns reveals anticipatory firing}

The results of the optimal time shift analyses demonstrate that LMN HD cell firing anticipates the future directional heading by $\sim 95$ msec. Using a different analytical approach, Blair and Sharp (1995) reported that ADN HD cells anticipate the rat's future directional heading by $\sim 25 \mathrm{msec}$. Their analysis was based on the observation that an ADN HD cell exhibits distinct preferred firing directions during $\mathrm{CW}$ and $\mathrm{CCW}$ head turns. This effect can be seen by studying the $\mathrm{CW}$ and $\mathrm{CCW}$ tuning curves for the
LMN HD cells depicted in Figure 4, $A$ and $B$. Note that in addition to the distinct peak firing rates the preferred firing direction for the $\mathrm{CCW}$ function is shifted to the left of the $\mathrm{CW}$ function. Such shifts during $\mathrm{CW}$ and $\mathrm{CCW}$ head turns indicate that the peak discharge rate of LMN HD cells is best associated with the animal's future directional heading. The mean $\partial$ for $\mathrm{LMN} \mathrm{HD}$ cells was $+25.03 \pm 2.63^{\circ}$ (range, $9.20-46.74^{\circ}$ ), which is consistent with the results of the optimal time shift analyses described above. For comparison, the mean $\partial$ values for $\mathrm{LMN}$, PoS, and ADN HD cells are presented in Table 2. A one-factor ANOVA yielded a significant effect of region on separation angle $\left(F_{(2,52)}=11.82 ; p<0.0002\right)$. Post hoc tests indicated that the $\partial$ values for $\mathrm{LMN}$ cells differed significantly from those of PoS cells but not from those of ADN cells. In addition, the analyses revealed significant differences between the PoS and ADN HD cells. Although there was no post hoc difference between LMN and ADN HD cells, LMN HD cells did have a higher mean $\partial$ value than ADN HD cells.

\section{Stability and cue card stimulus control}

In the presence of the salient white cue card LMN HD cells displayed stable preferred directions between distinct "standard" sessions. The preferred firing direction of LMN HD cells was also stable over days. For example, analysis of one cell recorded each day across 4 consecutive days showed that the cell maintained its preferred direction within $\pm 12^{\circ}$.

To evaluate the degree to which the polarizing cue card exhibits stimulus control over the preferred firing direction of LMN HD cells, we tested the responses of 16 cells after $90^{\circ}$ rotation of the cue card. For most LMN HD cells, a $90^{\circ}$ rotation of the cue card led to a corresponding shift in the preferred firing direction of the HD cell, with little change in the peak firing rate or directional firing range. All cells shifted their preferred direction at least $60^{\circ}$ after the $90^{\circ}$ cue rotation. The mean absolute deviation from the expected $90^{\circ} \mathrm{CCW}$ shift was $12.0 \pm 2.5^{\circ}$ (range, $\left.0-30^{\circ}\right)$. Of the 16 cells, the preferred direction shifted $>90^{\circ}$ for nine cells (over-rotation), shifted $<90^{\circ}$ for three cells (underrotation), and shifted exactly $90^{\circ}$ for four cells. When the cue card was returned to the standard position during the final standard session, the preferred firing directions of most cells shifted back to their initial values. The overall mean absolute deviation between the two standard sessions was $25.88 \pm 11.93^{\circ}$ (range, $0-144^{\circ}$ ). This mean deviation was influenced by the data from three cells that exhibited deviations between the two standard sessions of 66,138 , and $144^{\circ}$. If the data from these three deviant cells was removed, the mean absolute deviation between the two standard sessions was $5.1 \pm 1.6^{\circ}$ (range, $0-18^{\circ}$ ). In general, the responses of LMN HD cells after rotations of the cue card were 

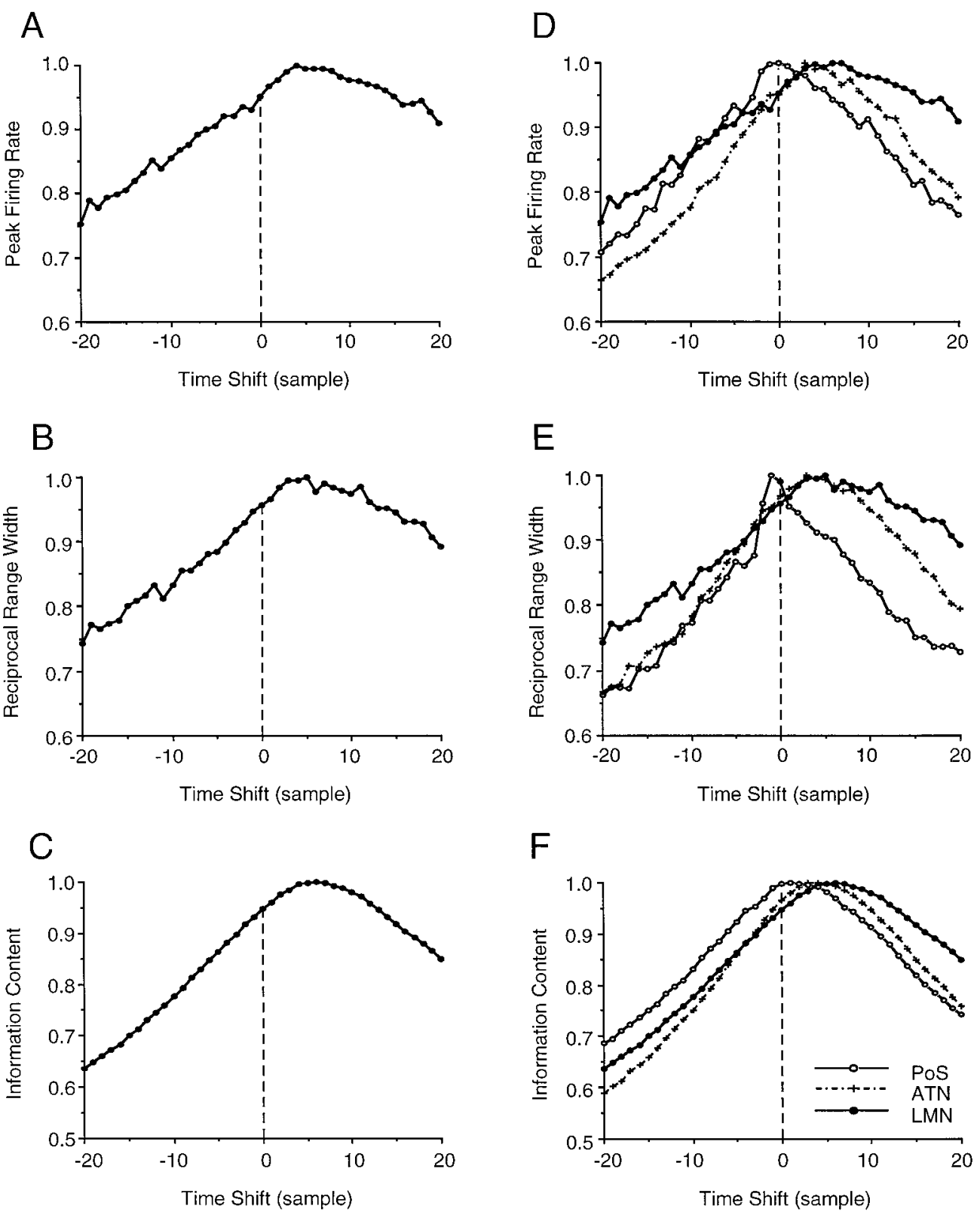

Figure 6. Normalized optimal time shift plots for the three parameters averaged across all LMN HD cells. $A$, Peak firing rate; $B$, reciprocal range width; $C$, directional information content. Plots $D-F$ compare the graphs from LMN HD cells ( filled circles) with graphs from PoS (open circles) and ADN ( plus symbols, dashed line) HD cells. These plots were constructed by normalizing the optimal function for each cell and then averaging across all cells of a given region. The resulting averaged function was then normalized a second time. Note that for all parameters, the optimal time shift for PoS cells is either negative or zero, and the optimal time shifts for ADN and LMN cells are positive. The plots for LMN cells indicate that they are shifted a little to the right of the plots for ADN cells.

similar to findings reported for ADN (Taube, 1995) and PoS HD cells (Taube et al., 1990b), demonstrating that the cue card exhibits strong stimulus control over the preferred firing directions of LMN HD cells.

\section{Head pitch cells}

The 14 cells classified as head pitch cells were recorded from three rats and were isolated from both left and right sides of the LMN. The firing rates of head pitch cells were independent of head direction. Qualitatively, most head pitch cells exhibited maximal firing when the rat pitched its head toward the ceiling (i.e., positive pitch). Discharge was not dependent on rearing, movement, food pellet consumption, or the rat's location within the cylinder. Pitch cells also continued to discharge while the rat was loosely wrapped in a towel and positioned in various body orientations with its head oriented toward the ceiling (i.e., head pitched up, body parallel with floor, etc.). The results of these assessments suggest that head pitch cell firing is independent of the rat's body position, indicating that head pitch cell firing cannot be attributed solely to the activation of neck proprioceptors.

Of the $14 \mathrm{LMN}$ head pitch cells recorded, 13 cells exhibited maximal discharge during head pitch in the positive direction (i.e., toward the ceiling); the remaining cell fired maximally when 
A

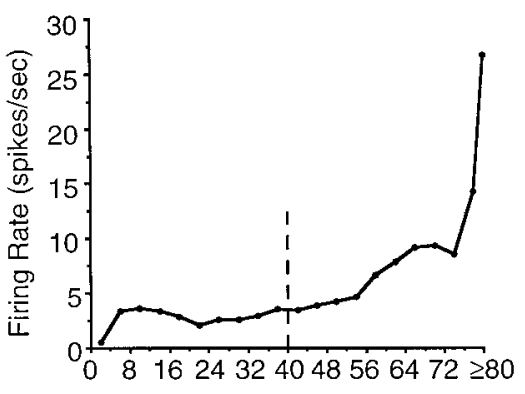

$\mathrm{B}$

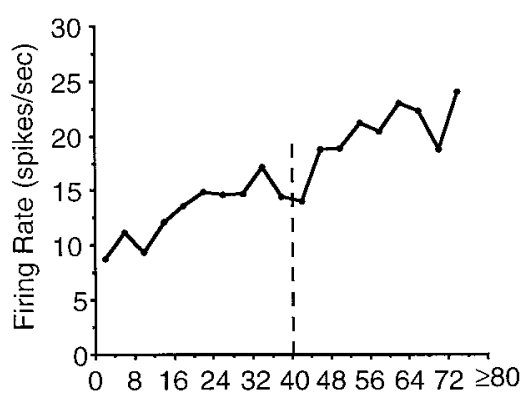

C

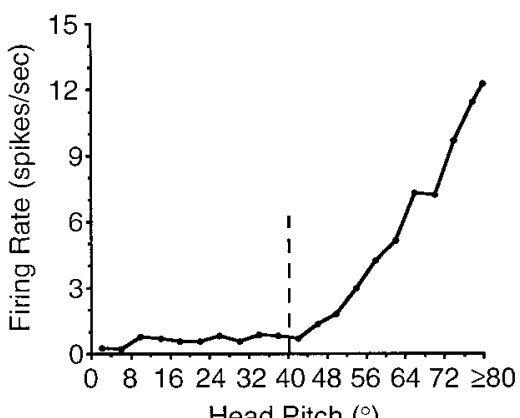

Head Pitch $\left({ }^{\circ}\right)$

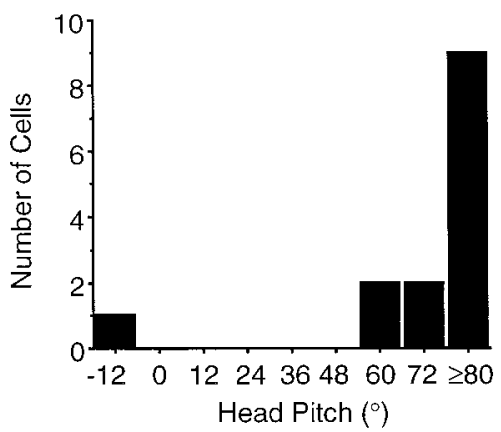

E

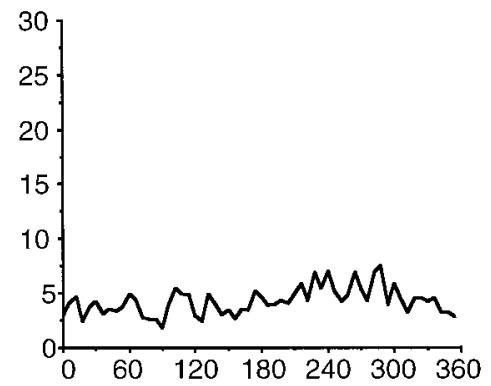

$\mathrm{F}$

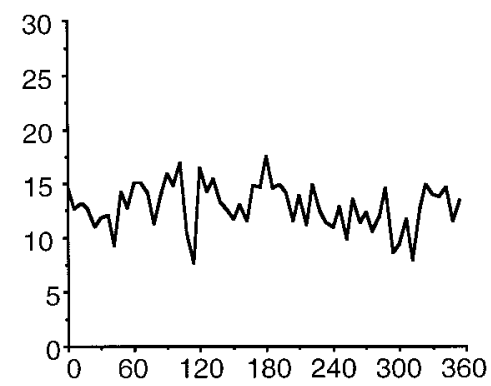

G

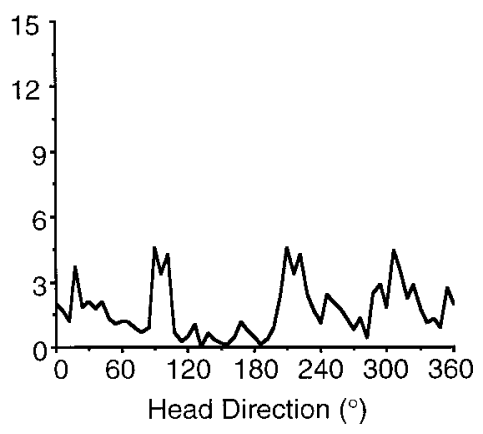

Figure 7. Firing rate as a function of head pitch for three representative nondirectional LMN head pitch cells $(A-C)$. Plots were generated from spike rate and head pitch (in $4^{\circ}$ bins) data collected during $16 \mathrm{~min}$ recording sessions. The preferred pitch (the head pitch value at which the cell discharged maximally) for each cell was $80^{\circ}(A) ; 74^{\circ}$ $(B)$; and $80^{\circ}(C)$. In each plot, the vertical dashed line represents the approximate cut-off indicating that head pitch values below $40^{\circ}$ were contaminated by negative head pitch values (i.e., pitching the head toward the floor). With respect to the cell depicted in $B$, no sampling occurred in head pitch bins $>74^{\circ}$ during the entire $16 \mathrm{~min}$ recording session. Head pitch values above $40^{\circ}$ represent only positive head pitch values (i.e., pitching the head toward the ceiling) (see Results for details). $D$, Histogram depicting the frequency distribution of preferred pitch values for the $14 \mathrm{LMN}$ head pitch cells. $E-G$, Firing rate versus head directiontuning functions for the three LMN head pitch cells depicted in $A-C$. the rat's head was pitched $-12^{\circ}$ vertical (i.e., toward the floor). Visual observations of the rat indicated that this cell exhibited peak firing only when the head pitch was $-12^{\circ}$ vertical and not when the head was $+12^{\circ}$ vertical. For each cell, we determined the preferred firing pitch as the head pitch at which the cell exhibited its maximal discharge rate. Figure $7 A-C$ illustrates firing rate by head pitch-tuning functions for three representative LMN head pitch cells. The preferred firing pitch of these cells was $+80,+74$, and $+80^{\circ}$, respectively. Although head pitch values of $\leq 40^{\circ}$ were contaminated by samples when the head was pitched down (see Materials and Methods), note that all three cells depicted in Figure $7 A-C$ exhibited peak discharge rates when the head was pitched $>40^{\circ}$. It is therefore unlikely that the high discharge rates above $40^{\circ}$ are attributed to instances of negative head pitch (i.e., head pitch down).

In general, the firing rate by head pitch-tuning functions indi- cate a nonlinear relationship between firing rate and head pitch. Specifically, most head pitch cells exhibited a minimal, if any, increase in firing rate as head pitch increased from 0 to $40^{\circ}$, and a considerable increase in firing rate as head pitch increased from $40^{\circ}$ to $\geq 80^{\circ}$ (e.g., head pitch-tuning functions depicted in Fig. $7 A, C)$. It is difficult to draw inferences regarding the linearity of the head pitch-tuning functions, given that head pitch values $<40^{\circ}$ are contaminated by negative pitch values. Quantitative measures of background firing rate and peak firing rate were determined from the firing rate by head pitch-tuning function of each cell. Background firing rate was taken as the mean firing rate for all head pitch data points $<40^{\circ}$. The background firing of the one head pitch cell with a preferred pitch of $-12^{\circ}$ was taken as the mean firing rate for all data points $>40^{\circ}$. The mean background firing rate for all 14 head pitch cells was $13.21 \pm 3.63$ spikes/sec (range, 0.61-46.47 spikes/sec). The mean peak firing rate of all 
LMN head pitch cells was $36.89 \pm 6.86$ spikes/sec (range, 5.2276.44 spikes/sec). Figure $7 D$ presents the frequency distribution of preferred firing pitches across the 14 head pitch cells. The frequency distribution indicates the greater likelihood of finding cells exhibiting preferred pitch values close to the maximal positive pitch (i.e., $+90^{\circ}$ vertical).

To assess the degree to which head pitch cells might convey information regarding head direction, we determined the directional information content value for each LMN head pitch cell. The mean directional information content of the head pitch cells was $0.10 \pm 0.03$ (range, 0.01-0.45). A $t$ test revealed that the mean directional information content value of head pitch cells was significantly different from that of LMN HD cells $(t(30)=-4.42$; $p<0.0001)$. Furthermore, observation of firing rate by head direction plots for head pitch cells failed to indicate any relationship between the two variables. Figure $7 E-G$ illustrates the HD by firing rate tuning functions for the three head pitch cells depicted in Figure $7 A-C$. These results indicate that a subpopulation of LMN neurons encode the extent of head pitch, independent of head direction.

We also assessed whether the discharge of LMN HD cells and angular head velocity cells (see below) were influenced by head pitch. Head pitch by firing rate plots were generated for both LMN HD and AHV cells. None of the plots showed any indication that these cells were modulated by head pitch. Figure $8 A-C$ illustrates representative firing rate by head pitch plots for an LMN HD cell (Fig. 8A) and for AHV cells (Fig. 8B,C).

\section{AHV cells}

The firing of AHV cells was directly proportional to the rat's angular head velocity. The discharge rates of these cells did not appear to be modulated by the rat's head pitch, directional heading, or by its spatial location in the cylinder. The AHV cells were recorded from 12 rats, from both the left and right sides of the LMN. Firing rate by angular head velocity plots indicated that there were two distinct populations of LMN AHV cells: (1) one group, termed slow AHV cells $(n=18)$, exhibited a negative correlation between firing rate and AHV (mean $r=-0.82$ ), that is, firing rates decreased with faster head turns; and (2) a second group, termed fast AHV cells $(n=20)$, exhibited a positive correlation between firing rate and AHV (mean $r=0.89$ ), that is, firing rates increased with faster head turns. The relationships of angular velocity and firing rate for these two AHV cell types were consistent across $\mathrm{CW}$ and $\mathrm{CCW}$ head turns, such that fast AHV cells, exhibited increased firing rates as angular head velocity increased from 0 to $270^{\circ} / \mathrm{sec}$ in either $\mathrm{CW}$ or $\mathrm{CCW}$ directions. Figure $9, A$ and $B$, depicts representative firing rate by angular velocity tuning functions for a slow AHV cell (Fig. 9A) and for a fast AHV cell (Fig. 9B). As these figures demonstrate, the relationship of AHV cell-firing rate to angular velocity was maintained whether the rat's head was turning $\mathrm{CW}$ or $\mathrm{CCW}$. Figure $9 C$ illustrates the influence of absolute angular head velocity (the data from $\mathrm{CW}$ and $\mathrm{CCW}$ head turns combined) on the firing rates of the two types of LMN AHV cells averaged across all cells for that category. This graph depicts the mean normalized firing rate \pm SEM for all slow AHV cells and for all fast AHV cells, determined by dividing the firing rates of each cell for each angular velocity interval by the mean firing rate of that cell during the recording session.

To quantitatively analyze AHV cells, slow AHV cells and fast AHV cells were treated as independent groups. For each AHV cell, angular head velocity was correlated with the mean firing
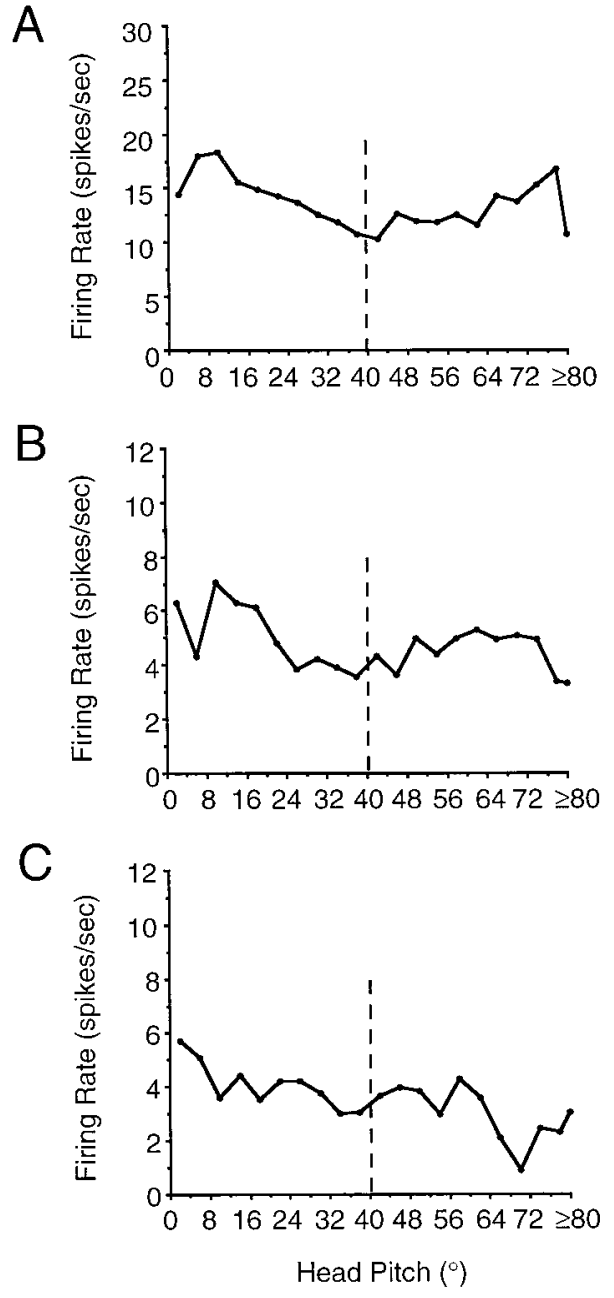

Figure 8. Firing rate versus head pitch-tuning functions for an LMN HD cell $(A)$, an LMN slow angular head velocity cell $(B)$, and an LMN fast angular head velocity cell $(C)$. These plots demonstrate that the firing rates of LMN HD and angular head velocity cells were not modulated by head pitch. The vertical dashed line represents the approximate cut-off indicating that head pitch values below $40^{\circ}$ were contaminated by negative head pitch values (see Results for details).

rate of the cell over a five sample episode. For both AHV cell types, $t$ tests revealed that the respective correlation values were not likely to arise from populations with expected values of zero (slow AHV cells: $t(17)=26.00, p<0.0002$; fast AHV cells: $t(19)$ $=49.42, p<0.0002)$. Despite the distinct firing correlates of the two types of AHV cells, the maximal observed firing rates did not differ between the two cell groups $(t(36)=0.85$, NS) (slow AHV cells $=14.37$ spikes $/ \mathrm{sec}$; fast AHV cells $=18.08$ spikes/sec $)$. A two-factor repeated measures ANOVA [AHV cell type (slow, fast), angular head velocity interval] revealed a significant effect of AHV cell type $\left(F_{(1,36)}=64.42 ; p<0.002\right)$, a significant AHV cell type $\times$ angular head velocity interval interaction $\left(F_{(3,108)}=\right.$ 42.44; $p<0.0002)$, but a nonsignificant effect of angular head velocity $\left(F_{(3,108)}=1.21\right.$, NS). Post hoc tests indicated that at each angular head velocity interval there was a significant difference in firing rate between slow AHV cells and fast AHV cells. These results indicate the presence of two distinct populations of LMN cells whose firing rates are differentially modulated by angular head velocity. Previous studies have demonstrated the existence of a small population of cells in the PoS that exhibit firing rates 

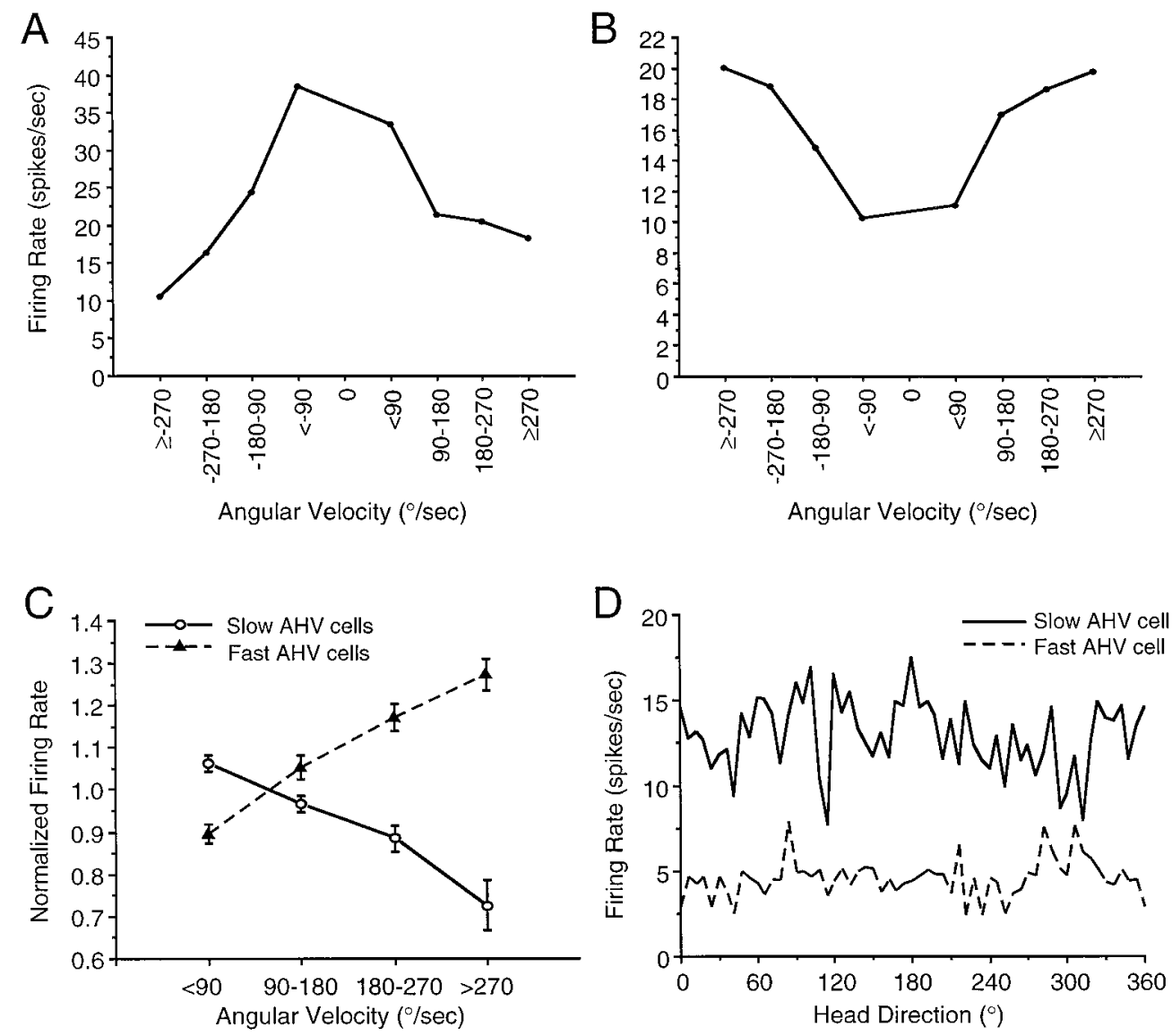

Figure 9. Influence of AHV on the firing rates of two populations of nondirectional LMN AHV cells. $A, B$, Firing rate as a function of angular velocity tuning functions of a slow AHV cell $(A)$ and of a fast AHV cell $(B)$. Firing rates were determined for each angular head velocity and grouped into $90^{\circ} / \mathrm{sec}$ intervals. Negative values refer to CW head turns, and positive values refer to CCW head turns. $C$, The firing rates of slow AHV cells (solid line, open circles) decreased with faster head turns, whereas the firing rates of fast AHV cells (dashed line, filled triangles) increased with faster head turns. The absolute values of angular velocity (clockwise and counterclockwise) were grouped into the four intervals shown, and the mean firing rates were determined for each interval. The plot depicts the mean normalized firing rate \pm SEM for slow AHV cells and for fast AHV cells, determined by dividing the firing rates of the cell for each angular velocity interval by the mean firing rate of that cell during that particular recording session. Post hoc multiple comparisons tests revealed significant differences between slow AHV cells and fast AHV cells at each of the four angular head velocity intervals. For graphical clarity, asterisks to indicate significant differences were omitted from this plot. $D$, Representative firing rate by HD-tuning functions for a slow AHV cell (solid line) and a fast AHV cell (dashed line). The plot indicates that neither AHV cell was modulated by the rat's directional heading.

modulated by angular velocity, independent of the animal's directional heading (Sharp, 1996).

To assess the degree to which AHV cells might convey information regarding head direction, we determined the directional information content value and firing rate by head direction-tuning functions for each LMN AHV cell. The mean directional information content of the AHV cells was $0.06 \pm 0.01$ (range, 0.0050.52 ) [the mean for slow AHV cells was $0.07 \pm 0.03$, and the mean for fast AHV cells was $0.05 \pm 0.01]$. Figure $9 D$ illustrates representative firing rate by $\mathrm{HD}$ tuning functions for a slow $\mathrm{AHV}$ cell and for a fast AHV cell. All but one of the AHV cells failed to exhibit directional firing. The remaining AHV cell, with a directional information content value of 0.52 , appeared to exhibit inconsistent directionality. Specifically, this AHV cell exhibited directional firing in two $6^{\circ}$ bins during an initial recording session, but during a subsequent recording session, this cell failed to exhibit directional firing. Examination of firing rate by HD plots for all other AHV cells failed to indicate any relationship between the two variables. Furthermore, a $t$ test revealed that the mean directional information content value of AHV cells was significantly different from that of LMN HD cells $(t(56)=-7.81$; $p<0.0001)$. Taken together, these results indicate that a subpopulation of LMN neurons encode angular head velocity, independent of head direction.

We also assessed the degree to which the firing rates of head pitch cells were influenced by angular head velocity. Interestingly, firing rate by angular head velocity analysis of the 14 head pitch cells yielded a mean $r_{\text {av }}$ value of 0.41 . Furthermore, inspection of individual firing rate by angular velocity plots indicated that 6 of the 14 head pitch cells exhibited a negative correlation between firing rate and angular velocity (mean $r_{\mathrm{av}}=-0.92$ ), that is, firing rates decreased with faster head turns; whereas the remaining eight head pitch cells exhibited a positive correlation between firing rate and angular velocity (mean $r_{\text {av }}=0.70$ ), indicating that firing rates increased with faster head turns. Thus, head pitch cells appear to convey information regarding both pitch and angular velocity of the head.

\section{DISCUSSION}

This experiment was designed to determine the firing properties of LMN single units in the freely moving rat. The rationale was based on neuroanatomical evidence indicating that the LMN may 
be a component of an alternate pathway by which vestibular signals access the HD cell circuitry and that LMN send and receive projections to and from structures containing HD cells. Our results demonstrate the existence of at least three classes of spatial signals within the LMN: (1) neurons that discharge as a function of head direction in the horizontal plane, irrespective of spatial location (HD cells), (2) neurons that discharge as a function of head pitch in the vertical plane (head pitch cells), and (3) neurons that discharge as a function of angular head velocity (AHV cells). Compared to HD cells recorded from the PoS and ADN, the LMN HD cells were found to exhibit significantly higher peak firing rates and greater directional firing ranges. The wider directional firing range of LMN HD cells suggests a more coarse coding of directional heading by the LMN than that represented by PoS or ADN HD cells.

Two aspects of head-turning behavior were found to influence LMN HD cells. First, although LMN HD cells discharged from both $\mathrm{CW}$ and $\mathrm{CCW}$ directions as the rat's head approached the preferred direction, firing rates were higher for one direction of turn. Furthermore, this modulation correlated with the side of the LMN the cell resided, with right LMN cells having higher firing rates for $\mathrm{CW}$ head turns and left LMN cells having higher firing rates for $\mathrm{CCW}$ head turns. Second, LMN HD cells were modulated by angular velocity, such that firing rates increased during faster head turns. Therefore, the firing rates of LMN HD cells reflect both the current angular head velocity and the direction (CW, CCW) of head turning. Although angular head velocity modulation of HD cells is apparent in the ADN but not in the PoS, HD cells in neither of these areas encode for head turn direction (Taube, 1995; Blair and Sharp, 1995).

In addition to the angular velocity modulation of HD cells, we recorded nondirectional LMN units whose discharge properties were also influenced by angular velocity. A small population of cells with similar response properties have been recorded from the PoS (Sharp, 1996). Given that a large percentage of LMN neurons exhibited firing rates influenced by angular velocity, perhaps one of the primary functions of the LMN is to process angular velocity information and integrate it with directional heading information encoded by LMN HD cells. Indeed, it has been hypothesized that the integration of angular velocity information from the vestibular system is necessary for the maintenance of an internal representation of directional heading in the absence of familiar landmark cues (McNaughton et al., 1991, 1996; Redish et al., 1996). Cells present in the LMN coding for $\mathrm{HD}$ and AHV enable the representation of these two pieces of information.

McNaughton et al. (1996), Samsonovich and McNaughton (1997), and Redish et al. (1996) have postulated similar system level models that are capable of updating an animal's current location and directional heading as it moves through the environment. In the McNaughton et al. (1996) model, the HD cell system is based on an attractor network that is modulated by two types of input: (1) HD by rotation cells [referred to as $\mathrm{H}^{\prime} \mathrm{H}$ cells (cells that discharge in relation to both azimuth and the direction of head rotation in the horizontal plane) in their Fig. 5] and (2) an external sensory landmark system, which is primarily visual. The $\mathrm{HD}$ by rotation signal is composed of inputs from AHV cells, derived primarily from vestibular information, and reciprocal connections from HD cells. Our present data indicate that the basic components of this architecture are present within the LMN. For example, the LMN HD cells that were modulated by turn direction contain the characteristics required of $\mathrm{HD}$ by rotation cells, although it is noteworthy that not all LMN HD cells were modulated by turn direction. Furthermore, the properties of LMN AHV cells reflect the type of information that is projected onto HD by rotation cells. Our previous findings that labyrinthectomies abolish ADN HD cell firing (Stackman and Taube, 1997), along with the findings that the ADN receives a dense projection from the LMN (Hayakawa and Zyo, 1989; Shibata, 1992; Guison et al., 1995), also provide support for this hypothesis. Because the connectivity of $\mathrm{HD}$ and AHV cells within the LMN, as well as with the ADN, is unknown, one can only speculate about the degree to which these cell types communicate with one another both within a given structure and across structures. It will be important for future studies to determine how these spatial cells are interconnected with one another. Finally, current models of the HD cell system only include AHV cells of the fast AHV type, and future models will need to include cells containing slow AHV characteristics.

The neuroanatomical connections between brainstem vestibular nuclei and LMN HD and AHV cells are not well known. However, the differences in response properties of neurons in the left and right vestibular nuclei during ipsilateral and contralateral head turns could provide distinct turn-modulated input to the LMN, as described above in the Results. Because ADN HD cells do not exhibit turn-modulated firing rates, it is conceivable that the bilateral LMN innervation of the ADN conveys turnmodulated LMN HD cell output to the ADN on both sides of the brain, resulting in net input to the ADN that is devoid of distinct head-turning information. However, this possibility stands in contrast to current theoretical models that were designed to account for the anticipatory properties of ADN HD cells (Redish et al., 1996; Blair et al., 1997).

Differential input from LMN AHV cells to LMN HD cells might be responsible for the angular velocity modulation of LMN HD cells. Specifically, angular velocity modulation of HD cellfiring rates could be produced if LMN HD cells were inhibited by slow AHV cells and excited by fast AHV cells. It is also possible that similar output connections of slow AHV and fast AHV cells to the ADN could support angular velocity modulation of ADN HD cells.

HD cells in the ADN and PoS are considered to be essential components of a neural circuit (as outlined in Fig. 10) that supports landmark-based navigation and inertial navigation (path integration) (Barlow, 1964; Gallistel, 1990; see Taube et al., 1996 for a review of relation of HD cells to navigation). As mentioned earlier, vestibular input to the HD cell circuit is necessary for the directional discharge of ADN HD cells (Stackman and Taube, 1997). The present results identify two mechanisms whereby vestibular information may be conveyed to the HD cell circuit. Signals from LMN angular velocity-modulated HD cells and AHV cells could be integrated in the ADN via the mammillothalamic tract as a substrate for path integration. It is interesting to note that much of the circuitry represented in Figure 10 is the well defined Papez circuit (Papez, 1937). The Papez circuit, proposed to be critical for emotional processes, was defined as a loop connecting the anterior thalamic nuclei with the cingulate cortex, hippocampus, and mammillary bodies, with the mammillothalamic tract closing the loop back to the anterior thalamus. Empirical evidence has instead implicated a role for each of the Papez circuit structures in spatial learning and memory processes (Aggleton et al., 1996; Neave et al., 1997; Sziklas and Petrides, 1998). Furthermore, based on neurophysiological data it appears 


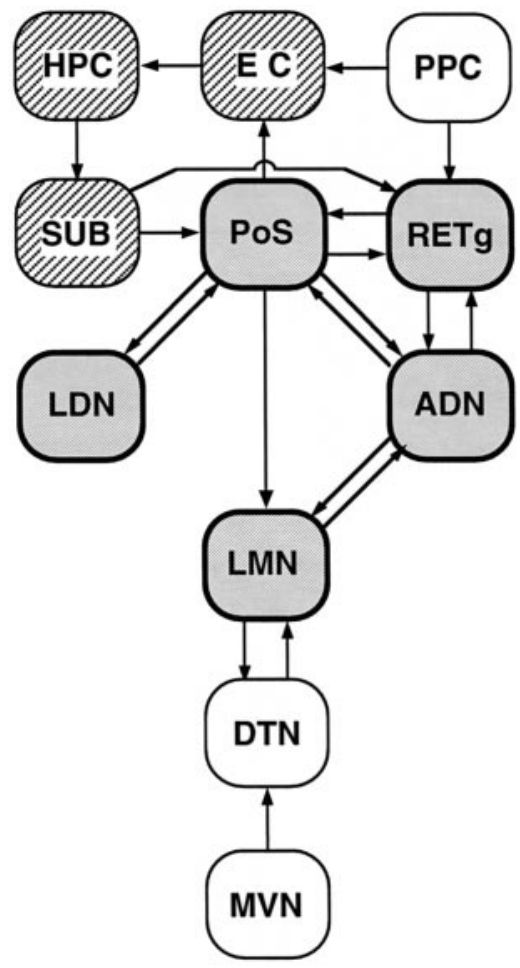

Figure 10. A schematic diagram illustrating the anatomical connections among structures that may comprise a limbic circuit processing allocentric spatial information. The heavily outlined, shaded boxes represent structures from which HD cells have been recorded; the striped boxes represent structures containing neurons whose firing is dependent on location (i.e., place cells). These two distinct cell types, conveying representations of location and directional heading, may provide information to support spatial memory and navigation. As discussed in the introductory remarks, idiothetic cue sources, such as vestibular information, may impinge on the HD cell-containing network by way of projections from brainstem structures. Vestibular input is critical for the ADN HD cell firing (Stackman and Taube, 1997), and this diagram suggests a disynaptic pathway (MVN $\rightarrow$ DTN $\rightarrow$ LMN) by which vestibular signals could influence the HD cell circuitry. In contrast, landmark-based cue information might be conveyed to the HD cell circuit via input from devoted cortical regions, such as the visual, tactile, and auditory cortices, converging on the posterior parietal cortex (PPC). The arrows between boxes indicate the flow of information between structures and are based on the anatomical literature. $A D N$, Anterior dorsal nucleus of thalamus; $D T N$, dorsal tegmental nucleus; $E C$, entorhinal cortex; $H P C$, hippocampus; $L D N$, lateral dorsal nucleus of thalamus; $L M N$, lateral mammillary nucleus; $M V N$, medial vestibular nucleus; PoS, postsubiculum; PPC, posterior parietal cortex; RETg, retrosplenial granular cortex; $S U B$, subiculum.

that a neural network that may support spatial memory and navigational processes is contained within the Papez circuit.

The firing rates of LMH HD cells best reflected the animal's future head direction by an average of $\sim 95 \mathrm{msec}$. This value is considerably more anticipatory than the +25 and $0 \mathrm{msec}$ values reported for $\mathrm{ADN}$ and $\mathrm{PoS} \mathrm{HD}$ cells, respectively (Blair and Sharp, 1995; Blair et al., 1997; Taube and Muller, 1998). Blair and Sharp (1995) proposed that anticipatory ADN HD cell firing is accomplished by a thalamocortical circuit that integrates current HD and angular head motion at the level of the ADN. It is interesting to note that such angular path integration of directional heading could also be achieved by the integration of an angular velocity signal in the LMN with a current HD signal via a direct input from the PoS to the LMN (Allen and Hopkins, 1989; Shibata, 1989).
Both the anatomical data and the time shift analyses suggest that the flow of information for the generation of the HD cell signal in the PoS may be $\mathrm{LMN} \rightarrow \mathrm{ADN} \rightarrow$ PoS. In support of this possibility, Goodridge and Taube (1997) reported intact ADN HD cell firing after PoS lesions; however, the ADN HD cells exhibited wider directional firing ranges and larger optimal time shifts and suggest that the firing properties of ADN HD cells in PoS-lesioned rats are more consistent with properties of LMN HD cells. Without PoS input, ADN HD cells may be more influenced by the anticipatory and directional firing properties of LMN HD cells. To fully appreciate the nature of mammillary involvement in the generation of the HD cell signal, it would be interesting to record PoS and ADN HD cells in rats after lesions or temporary inactivation of the LMN.

The exciting finding of head pitch cells in the LMN provides further support that LMN units represent the relative head position in both horizontal and vertical planes, and in allocentric as well as egocentric reference frames. The head pitch cell-firing properties were stable over the entire surface of the cylinder floor and across several recording sessions. Based on our assessments, we feel that it is likely that this class of cells is responding to head pitch and not some artifact of the recording environment. Although it is tempting to speculate that a population of LMN head pitch cells encodes the rat's head orientation in the vertical dimension, our finding that the majority of head pitch cells exhibited peak firing rates when the rat oriented its head near $90^{\circ}$ vertical, argues against this notion. Indeed, the skewed distribution of the preferred pitch frequency histogram suggests that head pitch cells encode other types of information, and the functional significance of these cells remains unclear. For this reason it will be important for future studies to explore the sensory and motor properties which control their activity. Finally, although one could speculate about the existence of cells that receive input from both HD cells and head pitch cells, thereby providing a head direction by head pitch representation, none of the LMN HD cells we recorded were modulated by head pitch.

In conclusion, the present study determined that populations of rat LMN cells encode directional heading, angular head velocity, and head pitch. The discharge properties of LMN HD cells appear to be somewhat different from those of PoS and ADN HD cells. Specifically, LMN HD cells have wider firing ranges, are modulated by angular velocity and turn direction, and exhibit larger anticipatory properties than ADN and PoS HD cells. The robust firing of LMN AHV cells and head pitch cells indicates that neurons within the LMN code additional aspects of angular head motion and head position. Given the presence of strong interconnections between the $\mathrm{LMN}, \mathrm{ADN}$, and PoS, it is likely that these types of LMN cells influence the output of the HD cell circuitry and may be particularly relevant for spatial information processing.

\section{REFERENCES}

Abraham L, Copack PB, Gilman S (1977) Brain stem pathways for vestibular projections to cerebral cortex in the cat. Exp Neurol 55:436-448.

Aggleton JP, Hunt PR, Shaw C (1990) The effects of mammillary body and combined amygdalar-fornix lesions on tests of delayed nonmatching-to-sample in the rat. Behav Brain Res 40:145-157.

Aggleton JP, Hunt PR, Nagle S, Neave N (1996) The effects of selective lesions within the anterior thalamic nuclei on spatial memory in the rat. Behav Brain Res 81:189-198.

Allen GV, Hopkins DA (1989) Mamillary body in the rat: topography and synaptology of projections from the subicular complex, prefrontal cortex, and midbrain tegmentum. J Comp Neurol 286:311-336. 
Andersen RA, Essick GK, Siegel RM (1985) Encoding of spatial location by posterior parietal neurons. Science 230:456-458.

Barlow JS (1964) Inertial navigation as a basis for animal navigation. J Theor Biol 6:76-117.

Batschelet E (1981) Circular statistics in biology. New York: Academic.

Blair HT, Sharp PE (1995) Anticipatory head direction signals in anterior thalamus: evidence for a thalamocortical circuit that integrates angular head motion to compute head direction. J Neurosci 15:6260-6270.

Blair HT, Lipscomb BW, Sharp PE (1997) Anticipatory time intervals of head-direction cells in the anterior thalamus of the rat: implications for path integration in the head-direction circuit. J Neurophysiol 78:145-159.

Büttner U, Lang W (1979) The vestibulocortical pathway: neurophysiological and anatomical studies in the monkey. Prog Brain Res 50:581-588.

Chen LL, Lin LH, Green EJ, Barnes CA, McNaughton BL (1994) Head-direction cells in the rat posterior cortex. I. Anatomical distribution and behavioral modulation. Exp Brain Res 101:8-23.

Gallistel CR (1990) The organization of learning. Cambridge, MA: MIT.

Gonzalo-Ruiz A, Alonso A, Sanz JM, Llinas RR (1992) Afferent projections to the mammillary complex of the rat, with special reference to those from surrounding hypothalamic regions. J Comp Neurol 321:277-299.

Goodridge JP, Taube JS (1997) Interaction between the postsubiculum and anterior thalamus in the generation of head direction cell activity. J Neurosci 17:9315-9330.

Grüsser O-J, Pause M, Schreiter U (1990) Localization and responses of neurones in the parieto-insular vestibular cortex of awake monkeys (Macaca fascicularis). J Physiol (Lond) 430:537-557.

Guison NG, Ahmed AF, Dong K, Yamadori T (1995) Projections from the lateral mammillary nucleus to the anterodorsal thalamic nucleus in the rat. Kobe J Med Sci 41:213-220.

Hayakawa T, Zyo K (1989) Retrograde double-labeling study of the mammillothalamic and the mammillotegmental projection in the rat. J Comp Neurol 284:1-11.

Kocsis B, Vertes RP (1994) Characterization of neurons of the supramammillary nucleus and mammillary body that discharge rhythmically with the hippocampal theta rhythm in the rat. J Neurosci 14:7040-7052.

Kubie JL (1984) A driveable bundle of microwires for collecting singleunit data from freely-moving rats. Physiol Behav 32:115-118.

Lang W, Büttner-Ennever JA, Büttner U (1979) Vestibular projections to the monkey thalamus: an autoradiographic study. Brain Res 177:3-17.

Liu R, Chang L, Wickern G (1984) The dorsal tegmental nucleus: an axoplasmic transport study. Brain Res 310:123-132.

Llinas RR, Alonso A (1992) Electrophysiology of the mammillary complex in vitro I. Tuberomammillary and lateral mammillary neurons. J Neurophysiol 68:1307-1320.

McNaughton BL, Chen LL, Markus EJ (1991) "Dead reckoning", landmark learning, and the sense of direction: a neurophysiological and computational hypothesis. J Cognit Neurosci 3:190-202.

McNaughton BL, Barnes CA, Gerrard J, Gothard K, Jung MW, Knierim JJ, Kudrimoti H, Qin Y, Skaggs WE, Suster M, Weaver KL (1996) Deciphering the hippocampal polyglot: the hippocampus as a path integration system. J Exp Biol 199:173-185.

McNaughton N, Logan B, Panickar KS, Kirk IJ, Pan W-X, Brown NT, Heenan A (1995) Contribution of synapses in the medial supramammillary nucleus to the frequency of hippocampal theta rhythm in freely moving rats. Hippocampus 5:534-545.

Mizumori SJY, Cooper BG (1995) Spatial representations of dorsal caudate neurons of freely-behaving rats. Soc Neurosci Abstr 21:1929.

Mizumori SJY, Williams JD (1993) Directionally selective mnemonic properties of neurons in the lateral dorsal nucleus of the thalamus of rats. J Neurosci 13:4015-4028.

Muller RU, Kubie JL, Ranck Jr JB (1987) Spatial firing patterns of hippocampal complex spike cells in a fixed environment. J Neurosci 7:1935-1950.

Neave N, Nagle S, Aggleton JP (1997) Evidence for the involvement of the mammillary bodies and cingulum bundle in allocentric spatial processing by rats. Eur J Neurosci 9:941-955.

O'Keefe J (1976) Place units in the hippocampus of the freely moving rat. Exp Neurol 51:78-109.

Papez JW (1937) A proposed mechanism of emotion. Arch Neurol Psychiatry 38:725-743.

Paxinos G, Watson C (1998) The rat brain in stereotaxic coordinates, Ed 4. New York: Academic.

Ranck Jr JB (1973) Studies on single neurons in dorsal hippocampal formation and septum in unrestrained rats. I. Behavioral correlates and firing repertoires. Exp Neurol 41:461-535.

Redish AD, Elga AN, Touretzky DS (1996) A coupled attractor model of the rodent head direction system. Network: Comput Neural Sys 7:671-685.

Samsonovich A, McNaughton BL (1997) Path integration and cognitive mapping in a continuous attractor neural network model. J Neurosci 17:5900-5920.

Sharp PE (1996) Multiple spatial/behavioral correlates for cells in the rat postsubiculum: multiple regression analysis and comparison to other hippocampal areas. Cereb Cortex 6:238-259.

Shibata H (1987) Ascending projection to the mammillary nuclei in the rat: a study using retrograde and anterograde transport of wheat germ agglutinin conjugated to horseradish peroxidase. J Comp Neurol 264:205-215.

Shibata H (1989) Descending projections to the mammillary nuclei in the rat, as studied by retrograde and anterograde transport of wheat germ agglutinin-horseradish peroxidase. J Comp Neurol 285:436-452.

Shibata H (1992) Topographic organization of subcortical projections to the anterior thalamic nuclei in the rat. J Comp Neurol 323:117-127.

Shibata H (1993) Direct projections from the anterior thalamic nuclei to the retrohippocampal region in the rat. J Comp Neurol 337:431-445.

Skaggs WE, McNaughton BL, Gothard KM, Markus EJ (1993) An information-theoretic approach to deciphering the hippocampal code. In: Advances in neural information processing 5 (Hanson SJ, Cowan JD, Giles CL, eds), pp 1030-1037. San Mateo, CA: Morgan Kaufman.

Stackman RW, Taube JS (1997) Firing properties of head direction cells in the rat anterior thalamic nucleus: dependence upon vestibular input. J Neurosci 17:4349-4358.

Swanson LW, Cowan WM (1977) An autoradiographic study of the organization of the efferent connections of the hippocampal formation in the rat. J Comp Neurol 172:49-84.

Sziklas V, Petrides M (1998) Memory and the region of the mammillary bodies. Prog Neurobiol 54:55-70.

Taube JS (1995) Head direction cells recorded in the anterior thalamic nuclei of freely moving rats. J Neurosci 15:70-86.

Taube JS, Muller RU (1998) Comparisons of head direction cell activity in the postsubiculum and anterior thalamus of freely moving rats. Hippocampus 8:87-108.

Taube JS, Muller RU, Ranck JB (1990a) Head direction cells recorded from the postsubiculum in freely moving rats. I. Description and quantitative analysis. J Neurosci 10:420-435.

Taube JS, Muller RU, Ranck JB (1990b) Head direction cells recorded from the postsubiculum in freely moving rats. II. The effects of environmental manipulations. J Neurosci 10:436-447.

Taube JS, Goodridge JP, Golob EJ, Dudchenko PA, Stackman RW (1996) Processing the head direction cell signal: a review and commentary. Brain Res Bull 40:477-486.

van Groen T, Wyss JM (1990) The postsubicular cortex in the rat: characterization of the fourth region of the subicular cortex and its connections. Brain Res 529:165-177.

van Groen T, Wyss JM (1992) Projections from the laterodorsal nucleus of the thalamus to the limbic and visual cortices in the rat. J Comp Neurol 324:427-448.

van Groen T, Wyss JM (1995) Projections from the anterodorsal and anteroventral nucleus of the thalamus to the limbic cortex in the rat. J Comp Neurol 358:584-604.

Wiener SI (1993) Spatial and behavioral correlates of striatal neurons in rats performing a self-initiated navigational task. J Neurosci 13:38023817. 